\title{
Smart Bionic Surfaces with Switchable Wettability and Applications
}

\author{
Shuyi Li, Yuyan Fan, Yan Liu*, Shichao Niu, Zhiwu Han, Luquan Ren \\ Key Laboratory of Bionic Engineering (Ministry of Education), Jilin University, Changchun 130022, China
}

\begin{abstract}
In order to satisfy the needs of different applications and more complex intelligent devices, smart control of surface wettability will be necessary and desirable, which gradually become a hot spot and focus in the field of interface wetting. Herein, we review interfacial wetting states related to switchable wettability on superwettable materials, including several classical wetting models and liquid adhesive behaviors based on the surface of natural creatures with special wettability. This review mainly focuses on the recent developments of the smart surfaces with switchable wettability and the corresponding regulatory mechanisms under external stimuli, which is mainly governed by the transformation of surface chemical composition and geometrical structures. Among that, various external stimuli such as physical stimulation (temperature, light, electric, magnetic, mechanical stress), chemical stimulation ( $\mathrm{pH}$, ion, solvent) and dual or multi-triggered stimulation have been sought out to realize the regulation of surface wettability. Moreover, we also summarize the applications of smart surfaces in different fields, such as oil/water separation, programmable transportation, anti-biofouling, detection and delivery, smart soft robotic etc. Furthermore, current limitations and future perspective in the development of smart wetting surfaces are also given. This review aims to offer deep insights into the recent developments and responsive mechanisms in smart biomimetic surfaces with switchable wettability under external various stimuli, so as to provide a guidance for the design of smart surfaces and expand the scope of both fundamental research and practical applications.
\end{abstract}

Keywords: bionic surfaces, external stimuli, switchable wettability, responsive mechanisms.

Copyright $(C)$ The author(s) 2021.

\section{Introduction}

Wettability is essential for many biological processes, tremendous engineering and industrial technologies ${ }^{[1-6]}$. The organism's systems have evolved for billions of years to develop strategies for impeccable structure-property-performance relations, which will provide excellent blueprints for bionic designs. Especially, lots of natural surfaces with special wettability have attracted the attention of numerous scientific researchers, such as lotus leaves, rose petals, slippery pitcher plants, mosquito compound eyes, rice leaf, water striders and so forth, exhibiting such excellent functions as self-cleaning, anti-fouling and drag reduction $\operatorname{etc}^{[7-15]}$. According to the investigations of underlying mechanism of these natural objects, numerous researches on constructing biomimetic super-antiwetting surfaces are mainly governed by the cooperation of chemical composition with low surface energy and surface microstructures, which are widely used in both fundamental research and practical applications ${ }^{[16-18]}$.
Up till now, researchers have developed various methods to construct artificial superwettable surfaces on different substrate, such as self-assembly, deposition, electro-spun, chemical-etching and so on ${ }^{[19-22]}$. However, most of studies on the surface wettability always are concentrated in single superhydrophobicity or superhydrophilicity. Recently, related researches on smart surfaces with dynamically switchable wettability in response to changes in surrounding environment have arose extensive attention on account of the wider range of industrial applications, such as the micro-fluidic devices, on-demanded oil/water separation, self-cleaning surfaces, lap-on-chip system, tunable optical lenses, and so forth ${ }^{[23-26]}$. Various external stimuli mainly including physical, chemical and dual or multi coupled factors can trigger the reversible wettability. Similar as the fabrication of superwetting surfaces, the transformation of surface chemical composition and geometrical structures fundamentally determines the switchable characteristics of wettability. Meanwhile, a variety of inorganic metal oxides and organic compounds usually are used as

\footnotetext{
*Corresponding author: Yan Liu

E-mail: lyyw@jlu.edu.cn
} 


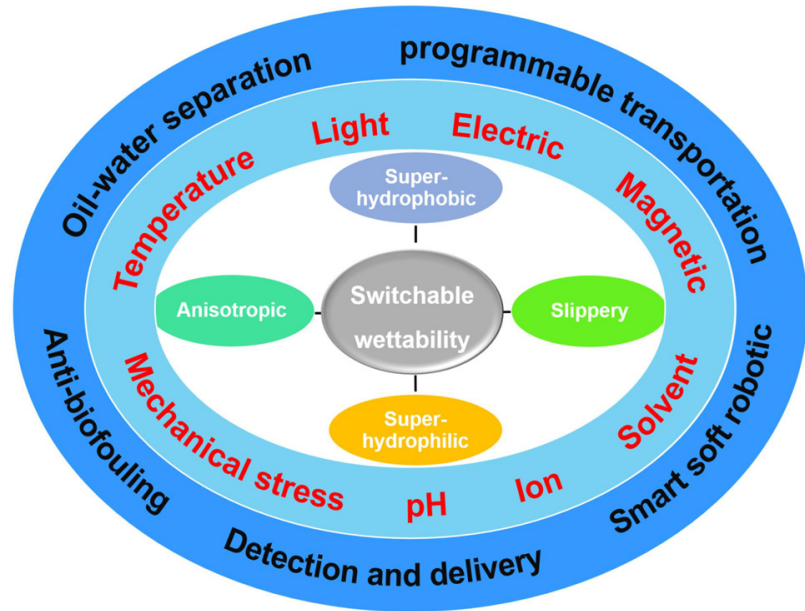

Fig. 1 Diagram of the categories of switchable wettability, including superhydrophobic, superhydrophilic, anisotropic and slippery. External stimuli consisting of physical stimulation (temperature, light, electric, magnetic, mechanical stress), chemical stimulation $(\mathrm{pH}$, ion, solvent) and dual or multi triggered stimulation will reduce the wettability transformation by changing the microstructures and chemical composition. All these studies can be applied in the field of oil/water separation, programmable transportation, anti-biofouling, detection and delivery, smart soft robotic.

stimuli-responsive substance ${ }^{[27-29]}$. By comparison, the organic polymers have advantages of not only more sensitive types (such as light, $\mathrm{pH}$, thermal), conformational transitions (trans-cis), but also being able to simultaneously control the surface energy and topography. However, due to the structural and photochemical stability of inorganic oxides, it is difficult to achieve a change in morphology by responding to the external stimuli. Whereas, the use of inorganic oxides is low toxic and more environmentally friendly with a larger range of wettability changes. Thus, there is an urgent need for new design principles and engineering strategies to develop artificial surfaces with adjustable superwettability and special adhesion to solve smart materials with characteristics similar to natural examples.

This review aims to provide a summary of the recent developments in smart surfaces with switchable wettability (Fig. 1), composed of the following sections. Firstly, several special superwetting states (superhydrophobicity, superhydrophilicity, underwater superoleophobicity, super-lubricity, and different adhesive property) based on the natural creatures are used to illustrate the structural features and wetting mechanisms related to the switchable wettability. Secondly, this re- view focuses on the recent progress of the smart surfaces with switchable wettability and the corresponding regulatory mechanisms under external stimuli, which mainly is governed by the transformation of surface chemical composition and geometrical structures. Meanwhile, the external factors and mechanism affecting interfacial wettability have been introduced in detail, consisting of physical stimulation (temperature, light, electric, magnetic, mechanical stress), chemical stimulation ( $\mathrm{pH}$, ion, solvent) and dual or multi triggered stimulation. Thirdly, our attentions have been paid to the applications and the correlative changes of surface chemical components / microstructures, as well as several characteristics of oil/water separation, programmable transportation, anti-biofouling, detection and delivery, smart soft robotic etc. Finally, we briefly summarize the challenges in the development of smart wetting surfaces at present and the development tendency in future.

\section{Mechanisms of interfacial superwettability on surfaces}

Research on wettability can be traced back to more than two decades ago, the classical liquid wetting theoretical models usually include the Young's model on smooth solid surface $(1805)^{[30]}$, Wenzel's model on rough surface (1936) ${ }^{[31]}$, and Cassie-Baxter model on inhomogeneous surface $(1944)^{[32]}$. Up to date, based on the early theories, numerous researchers gradually began to describe lots of different types of special wettability on the surfaces of plants or animals in nature. Especially, special superwetting states have been reported in the past decade, including superhydrophobicity, superhydrophilicity, underwater superoleophobicity, super-lubricity etc. Meanwhile, the superwetting surface not only requires the contact angle to be greater than $150^{\circ}$ for water or oil, but also reflects the hysteresis of the contact angle. Combined with the wettability property of typical creatures, the corresponding several special superwetting states shown in Fig. 2 will be expounded as follows.

The lotus leaf is considered a typical representative of superhydrophobic surfaces. There is an "air cushion" at the groove of micro-nanostructures to effectively reduce the contact area between water droplets and the 


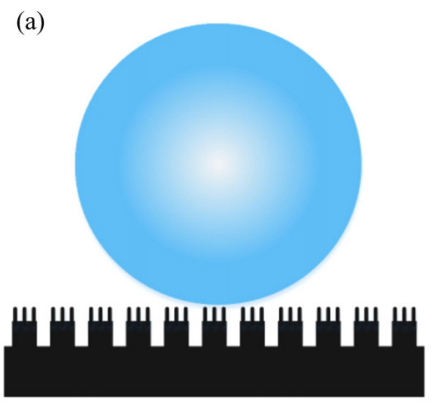

Superhydrophobicity low adhesion

(d)

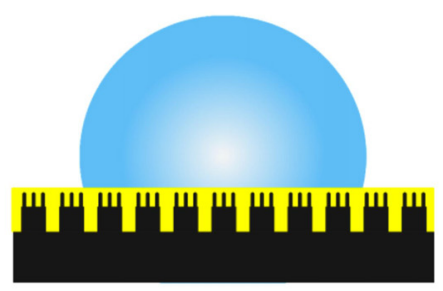

Slippery (b)
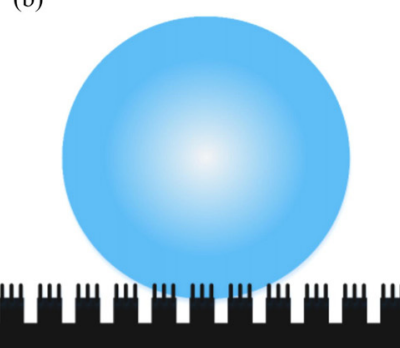

Superhydrophobicity high adhesion

(e)

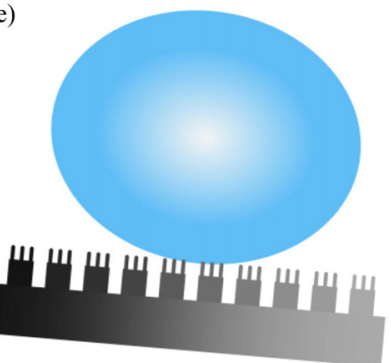

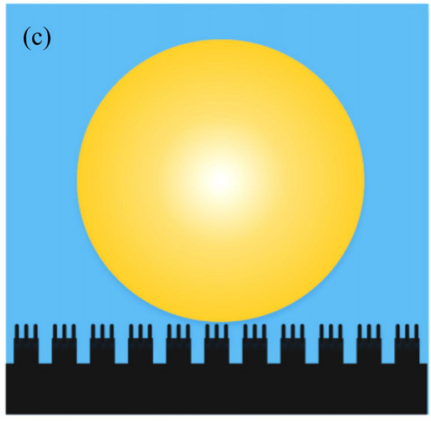

Superhydrophilicity underwater superoleophobicity

Superhydrophobicity anisotropic adhesion

Fig. 2 The illustration of different interfacial wetting states.

surfaces, thereby significantly inhibiting the lotus leaf from being wetted effectively and exhibiting super-hydrophobic self-cleaning phenomenon, which represents the special Cassie-Baxter state with ultra-low adhesion (Fig. 2a). Differently from the lotus effect, the surface of rose petals exhibits super-hydrophobic properties, but water droplets cannot move and be fixed on the surface. The small grooves among the micropillars are occupied with water and the large grooves among the nanofolds are forming an "air cushion" to maintain dry, which represents the wettability of Cassie impregnation state with high adhesion (Fig. 2b) ${ }^{[33]}$. Compared to the above water/air/solid interface, superhydrophilic fish scales surface exhibit underwater superoleophobicity because of the presence of water layer within the surface micro- and nanostructures instead of an air cushion, which can reduce the contact area between oil droplets and surface, thus preventing the adhesion of oil pollution $^{[34]}$ (Fig. 2c). Along with the extension of wettability research, introducing another immiscible liquid layer into solid surface microstructures also can realize the liquid repellency (Fig. 2d). Nepenthes pitcher plants with the Slippery Liquid-Infused Porous Surfaces (SLIPS), are difficult for insects to stop in the rim area and often "falling off" and slipping into the insect trap to be preyed ${ }^{[35]}$. Combined with the microtextural roughness, the surface of Nepenthes pitcher plant forms a highly stable lubricating layer, filling all the spaces in the texture, which is similar like the water layer on the fish scales. This feature allows it to repel and easily remove various liquids in the air ${ }^{[10]}$. Last but not least, compared with the isotropic rolling behavior of water droplets on the lotus leaf, the water droplets placed on the surface of the rice leaf and butterfly wings tend to fall along the direction parallel to the edge, exhibiting anisotropic superhydrophobicity, which resulting from the longitudinal grooves with a transverse sinusoidal pattern on rice leaves and aligned shingle-like scales on butterfly wings ${ }^{[8,36]}$. Unlike with the previous wetting state, the surface wettability presents the water droplets with a Cassie-like state and to form an extremely discontinuous Three-phase Contact Line (TCL) or a Wenzel-like state and to form a quasi-continuous TCL, respectively (Fig. 2e). The longitudinal grooves and scales on the rice 
leaves and butterfly wings effectively guide the droplets to roll directionally, resulting in the self-cleaning effect and inhibiting dust accumulation on the surfaces ${ }^{[37]}$. In the next section, this article will describe how to achieve intelligent switching between these wetting states by combining stimulus-responsive materials with microstructures or nanostructures, including the control of static wetting and dynamic wetting state.

\section{Stimuli-responsive on switchable wettability}

The wettability mechanisms of the above creatures provide an excellent reference for the design of superwetting surface, which will be useful for the explanation of relevant applications via the switchable wettability ${ }^{[38-40]}$. Smart switchable wettability of surface systems is reversibly triggered under various external stimuli, mainly including physical-responsive (temperature, light, electric field, magnetic field, stress, etc.) and chemical-responsive ( $\mathrm{pH}$, ion, solvents, etc.). Moreover, either single or dual or even multiple stimuli may work on a targeted property at the same time. This section will report and discuss various responsive mechanisms on the smart switchable wettability surface under different stimuli.

\subsection{Physical stimulation}

\subsubsection{Temperature}

The temperature-responsive substance without dependent on other chemical additives, can achieve a fast and intense reaction process to control the wettability transformation, exhibiting significant advantages compared to many other environmentally stimuli ${ }^{[41-43]}$. Large numbers of thermo-responsive surfaces with switchable wettability have been developed in the past few years via grafting temperature-sensitive polymers, such as poly(N-isopropylacrylamide) (PNIPAAm), poly(2-isopropyl-2-oxazoline), poly(vinyl methyl ether), and poly(2-(dimethylamino)-ethyl methacrylate (PDMAEMA) etc., which exhibit state conversion in higher or lower temperature than their Lower Critical Solution Temperature (LCST) respectively ${ }^{[44-46]}$. For instance, PNIPAAm with a LCST about $32{ }^{\circ} \mathrm{C}-33{ }^{\circ} \mathrm{C}$ is one of the utmost studied and widely used polymers for controlling the surface wettability ${ }^{[47,48]}$. Analyzing the thermo-driven wettability mechanism of the PNIPAAm, it is mainly due to the cooperation of intramolecular and intermolecular hydrogen bonding contributed by PNIPAAm chain. While the temperature is lower than the LCST, the surface is superhydrophilic, resulting from the effects of enthalpic contributions governed by comparing to the entropy contributions in this atmosphere, which is more likely to form intermolecular hydrogen between the $\mathrm{N}-\mathrm{H}$ and $\mathrm{C}=\mathrm{O}$ groups and water molecules. Oppositely, the entropy contributions will occupy the main position with a temperature above LCST, and the $\mathrm{N}-\mathrm{H}$ and $\mathrm{C}=\mathrm{O}$ groups preferentially form intramolecular hydrogen bonding, along with self-condensation and self-disintegration between the molecular chains to change into a collapsed conformation, repelling the water and exhibiting hydrophobicity. For example, Zhang et al. fabricated a thermo-responsive PNIPAAm-modified nylon membrane via hydrothermal method ${ }^{[49]}$. As shown in Fig. 3, by changing the temperatures lower or higher than the LCST, the switchable wettability of membrane exhibited the hydrophilicity and underwater superoleophobicity or hydrophobicity and superoleophilicity, so as to separate various stabilized oil-water emulsions effectively.

Especially, dynamic regulation of wettability reversibly also can be achieved by designing a special liquid, which can react with the functional surface in

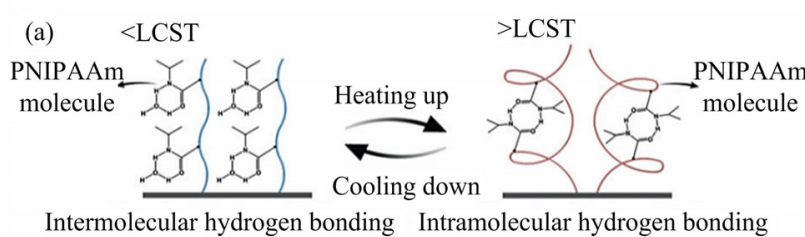

(b)

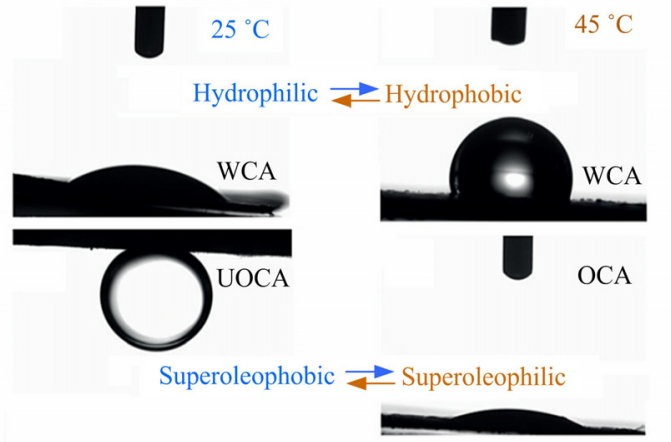

Fig. 3 (a) The responsive mechanism of the thermo-driven PNIPAAm; (b) the reversible wettability between the hydrophoilic/superoleophobic and hydrophobic/superoleophilic at $25{ }^{\circ} \mathrm{C}$ and $45{ }^{\circ} \mathrm{C}^{[49]}$. 
response to temperature. For example, by grafting the mixed molecular brushes of poly(phenylethyl methacrylate) and $1 \mathrm{H}, 1 \mathrm{H}, 2 \mathrm{H}, 2 \mathrm{H}$-perfluorodecyltrimethoxysilane (PPhEtMA-co-PFDMS) on the surface, Chang et al. first fabricated a thermo-induced surface, showing switchable wettability by an ion liquid (1-ethyl-3-methyl imidazolium bis(trifluoromethylsulfonyl)imide $([\mathrm{EMIm}][\mathrm{NTf} 2])^{[46]}$. The dynamical regulation of surface wettability was due to the changes of cation- $\pi$ interaction between [EMIm][NTf2] and PPhEtMA-co-PFDMS brushes under different temperature in Fig. 4a. Similarly, the conversion of dynamic surface wettability can also be achieved. Wang et al. directly designed a biological droplet adhesion system containing single-stranded DNA with reversible molecular configuration deformation under thermal stimuli, realizing the precisely controlment on the n-dodecane-infused slippery surface ${ }^{[50]}$. As shown in Fig. $4 \mathrm{~b}$, while increasing the temperature from $283 \mathrm{~K}$ to $303 \mathrm{~K}$, the flexibility and mobility of ssDNA were improved, along with the transformation of molecular conformation with the exposure limitation of hydrophobic moiety, which limit the interaction between the hydrophobic group and the lubricating molecule, thereby reducing interfacial adhesion.
In addition, several works on reversible superwetting transition were achieved by the heating treatment and remodification ${ }^{[51,52]}$. Notably, combined the removal of n-dodecanethiol (hydrophobic materials) at $350{ }^{\circ} \mathrm{C}$ and remodified at room temperature, Zhang et al. designed a biomimetic switchable wetting surface on AZ91D Mg alloy inspired by Lotus Seedpod ${ }^{[53]}$. Especially, different from the examples about the thermo-induced wettability mechanism mentioned above, Zhang et al. fabricated a superhydrophobic and superoleophilic nanoparticle film with reversible wettability via spray deposition, in which wetting transition from Cassie to Wenzel model is due to the water vapor condensation on the surface by adjusting the temperature ${ }^{[54]}$.

\subsubsection{Light}

As well known, the controlment of light has the characteristics of rapid contact, high resolution and remote controlment etc., so triggering changes in surface wettability through light-response has attracted widespread attention. The active molecules on the light-responsive material surface will occur reversible changes in chemical composition, chemical configuration or polarity etc., which can cause a change in the surface free energy, resulting in the reversible changes in

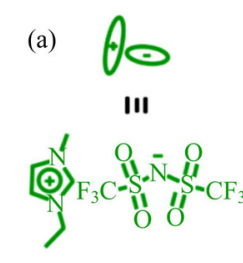

$[\mathrm{EMlm}]\left[\mathrm{NTf}_{2}\right]$

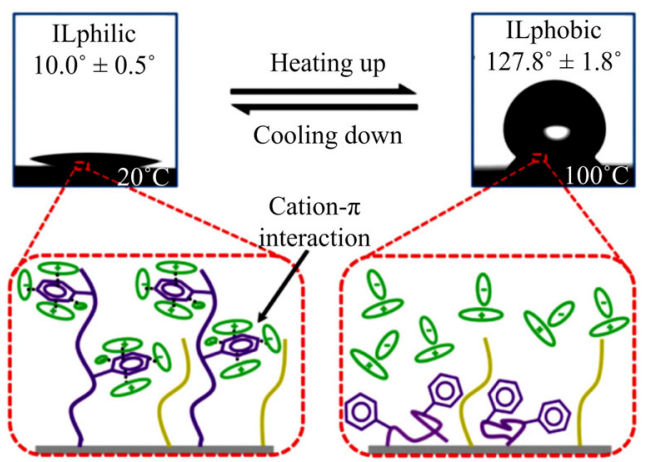

(b)
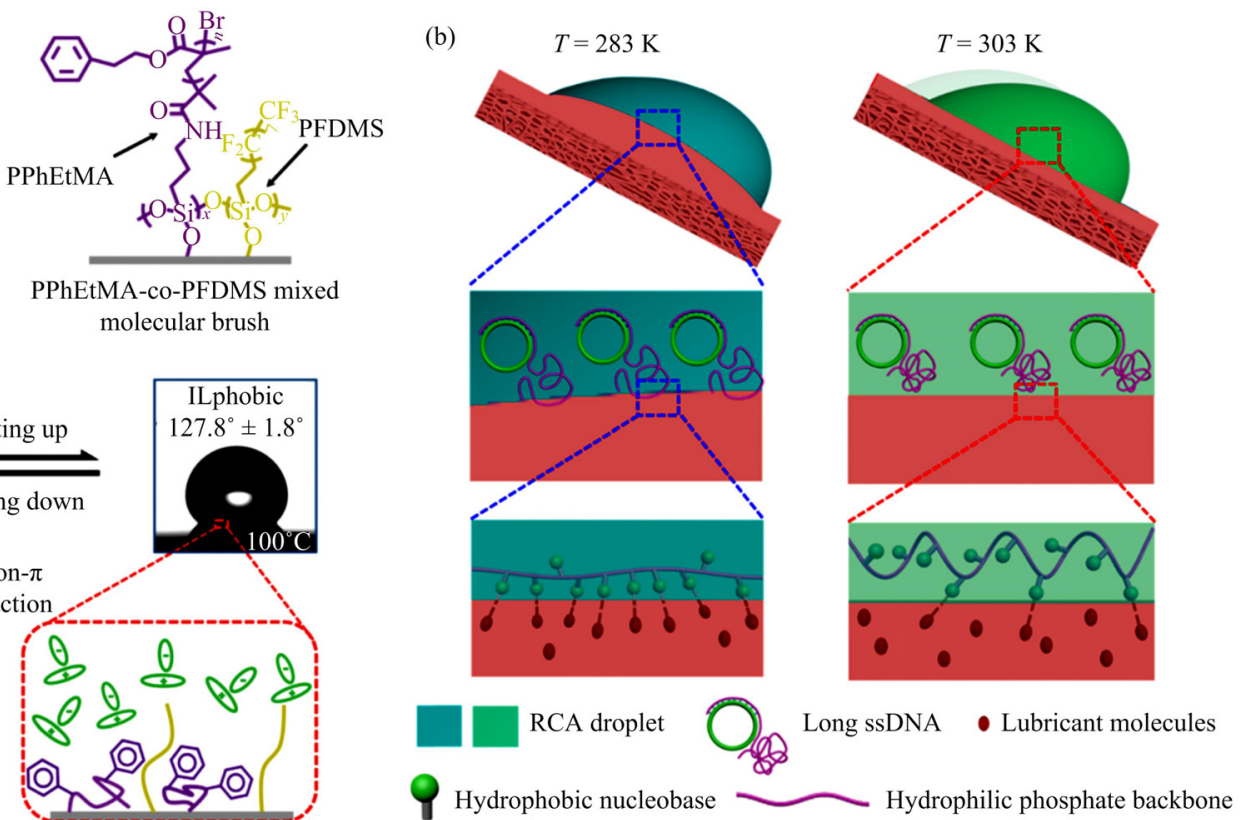

Fig. 4 (a) The dynamic regulation of temperature-responsive wettability by an ion liquid ([EMIm][NTf2] $)^{[46]}$; (b) schematic illustration of the hydrophobic interaction at the interface of biological droplet and n-dodecane under different temperature ${ }^{[50]}$. 
wettability.

The inorganic semiconductor oxide materials with optical triggering-yielded electron-hole pairs usually are used to regulate the reversible light-responsive wettability, such as titanium dioxide $\left(\mathrm{TiO}_{2}\right)$, zinc oxide $(\mathrm{ZnO})$, tin dioxide $\left(\mathrm{SnO}_{2}\right)$, tungsten trioxide $\left(\mathrm{WO}_{3}\right)$ and vanadium oxide $\left(\mathrm{V}_{2} \mathrm{O}_{5}\right)$ etc ${ }^{[29,55,56]}$. In the preparation of wettability-regulating superwettability surfaces, photosensitive inorganic semiconductor materials mainly utilize the free conversion of oxygen vacancies and hydroxyl groups under ultraviolet (UV) light irradiation and dark treatment (or heat treatment) to change the surface chemical polarity, thereby achieving the switchable wettability. The preparation method comprises the steps of preparing directly on the photosensitive material substrate, or grafting the photosensitive metal material nanoparticles on different substrates by a certain process ${ }^{[57,58]}$. Taken $\mathrm{TiO}_{2}$ as an example, the wetting transformation mechanism and the fabrication methods are explained briefly as follows. The electrons of $\mathrm{TiO}_{2}$ will be excited from the valence band to the conduction band under UV irradiation, and the photo-induced electron-hole pairs are generated, leading to the cleavage of $\mathrm{Ti}-\mathrm{O}$ bond, resulting in the formation of oxygen vacancies, thereby enhancing the adsorption of hydroxyl groups and some coexisting molecular water, so as to exhibit a superhydrophilic state (Fig. 5a) ${ }^{[29]}$. During heating process, the hydroxy groups are replaced by oxygen atoms that have a stronger bond on the defect sites, restoring the initial superhydrophobic properties. Kang et al. prepared $\mathrm{TiO}_{2}$ nanotube arrays on the $\mathrm{Ti}$ sheets via a simple anodizing and heating process in Fig 5b. Reversible transition between under-oil superhydrophilicity and under-oil superhydrophobicity can be realized by alternation of UV irradiation and heating treatment. Yong et al. fabricated regular micro/nanoscale hierarchical rough $\mathrm{TiO}_{2}$ structures on Ti substrate by femtosecond laser ablation, realizing the switchable underwater superoleophobicity-superoleophilicity by alternating UV irradiation and dark storage for the first time (Fig. 5c) ${ }^{[59]}$. Differently, as shown in Fig. 5d, via ultrasonic assisted dip coating, Li et al. fabricated an intelligent and robust sponge by grafting $\mathrm{TiO}_{2}$ nanoparticles and octadecanoic acid, achieving the properties of smart switchable super-wettability and effective oil-water separation under UV illumination and heating $^{[60]}$.

Except for inorganic compounds, several organic molecules also possess the characteristic of photo-responsive wettability with a shorter time to respond
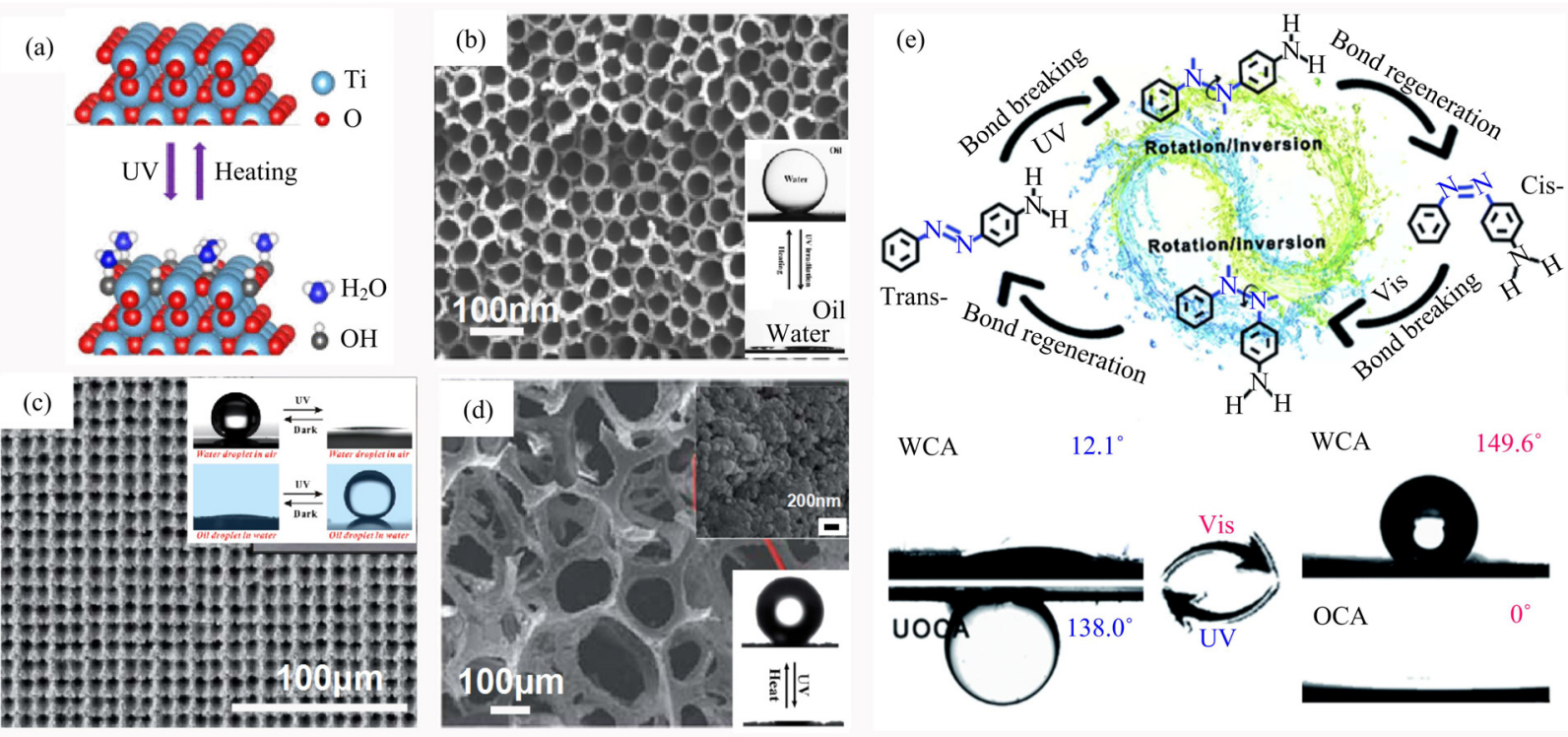

Fig. 5 (a) Schematic diagram of the anatase $\mathrm{TiO}_{2}(004)$ facet crystal structure variation under UV irradiation and heating, applying for the explanation of the light-induced transformation mechanism of surface wettability ${ }^{[29]}$. SEM images of $\mathrm{TiO}_{2}$ nanotube arrays fabricated by anodizing and heating $(\mathrm{b})^{[29]}$, femtosecond laser-ablated Ti surface $(\mathrm{c})^{[59]}$, sponge modified with $\mathrm{TiO}_{2}$ nanoparticles $(\mathrm{d})$ and the reversible wettability under UV irradiation and dark environment or heat treatment ${ }^{[69]}$. (e) The conformational conversion mechanism of photo-responsive organic molecules and wettability transformation of WCA/OCA changes on the modified copper mesh under UV and Vis light ${ }^{[61]}$. 
and recover, due to the photoisomerization-induced reversible conformational conversion and/or the dipole moment change, as well as spiropyran and azobenzene etc ${ }^{[62-65]}$. For example, azobenzene compounds with excellent trans-cis isomerism properties (shown in Fig. 5e), are easy to cause the transition of surface polarity under the irradiation of UV and visible light, thereby resulting in the regulation of surface wettability ${ }^{[27,61,66,67]}$. By means of modifying the nano-Ag pine needles and aminoazobenzene (AABN) on polydopamine (PDA) pre-treated porous meshes, functional surfaces with reversible photo-responsive wettability from highly hydrophobic to superhydrophilic were fabricated by Qu et al. ${ }^{[61]}$. The wettability transformation was ascribed to the alternate exposure of the hydrophilic group $(\mathrm{Ag})$ and hydrophobic benzene ring from AABN. Under $\mathrm{UV}$ irradiation, the $\mathrm{N}=\mathrm{N}$ bond of $\mathrm{AABN}$ was broken and rotated, resulting in the isomerization conversion from trans-form with molecule stood up straight to cis-form with molecule lying down, and exposing the hydrophilic Ag pine nano-needles. While irradiated by visible light, the molecule conformation was transformed into trans-form, and the initial highly hydrophobicity recovered again, revealing a larger transformation extent in reversible wettability.

\subsubsection{Electric}

Comparatively speaking, the stimuli of electric field possess the property of super-fast responsiveness and convenient controlment, causing the changes in the interfacial energy, which has powerful potential in the smart transition of surface wettability ${ }^{[68,69]}$.

One method is to modulate the droplet behavior through the electric-induced local molecular reorganization. Recently, lots of electric-responsive surface based on conducting polymer have been used to realize the switchable wettability, such as polythiophene (PT), polypyrrole (PPy), and polyaniline (PANI) etc ${ }^{[70-72]}$. Via the self-assembling of (16-Mercapto) hexadecanoic acid (MHA) onto the Au (111), Lahann et al. designed a surface with dynamically interfacial wettability in response to electric potential, which was caused by conformational transitions between hydrophilic and moderately hydrophobic state (Fig. 6a) ${ }^{[73]}$. Combined colloidal lithography with electrodeposited polythiophene derivatives, Pernites et al. fabricated a superhydrophobic polythiophene film with electric-responsive switchable wettability between hydrophilicity and superhydrophobicity by changing the redox property of conducting polymer, achieving the attachment or unattachment of both fibrinogen protein and Escherichia coli under the switching of on/off the low potential (1.05 V) (Fig 6b) ${ }^{[70]}$. Instead of the conducting polymer, changing the surface energy of conductive inorganic materials also can achieve the transformation in wettability. By electrodepositing tin layer on the copper electrode, Wang et al. obtained a copper/tin system with in situ reversible superwetting transition between underwater superhydrophilic and superoleophobic properties by electrochemical atomic alternation (Fig. 6c) ${ }^{[74]}$. The deposition of tin can significantly reduce the surface energy of the copper electrode and can be dissolved by removing the potential, thereby restoring the initial high energy state of the copper, which can realize the whole in situ reversible superwetting conversion via the switch of on/off potential.

The other route is directly applying the electrical field onto the liquid and conductive substrate to obtain the switchable wettability ${ }^{[75,76]}$. Krupenkin et al. demonstrated the dynamic electrical control over the wetting behavior on the nanostructured surface for the first time, transforming from superhydrophobic state to almost complete wetting under $22 \mathrm{~V}$ (Fig. 6d) ${ }^{[77]}$. The changes relied on the applied voltage and liquid surface tension, causing the liquid permeation in the nanostructure layer. In addition, Kavousanakis et al. demonstrated the reversible change of contact angle in response to an electric field was closely related with the thickness of the solid dielectric (Fig. 6e) ${ }^{[78]}$.

\subsubsection{Magnetic}

The magnetic-responsive process is easy to operate, low energy consumption, safety and fast responsiveness etc. Magnetic field-driven reversible wettability can dynamically control surface features by embedding magnetic particles or magnetic fluids ${ }^{[79,80]}$. The magnetic-induced mechanism is mainly attributed to the changes in surface microstructures ${ }^{[81-86]}$. Combining spray coating with magnetic-field-directed selfassembly, Yang et al. fabricated a magnetic-responsive 

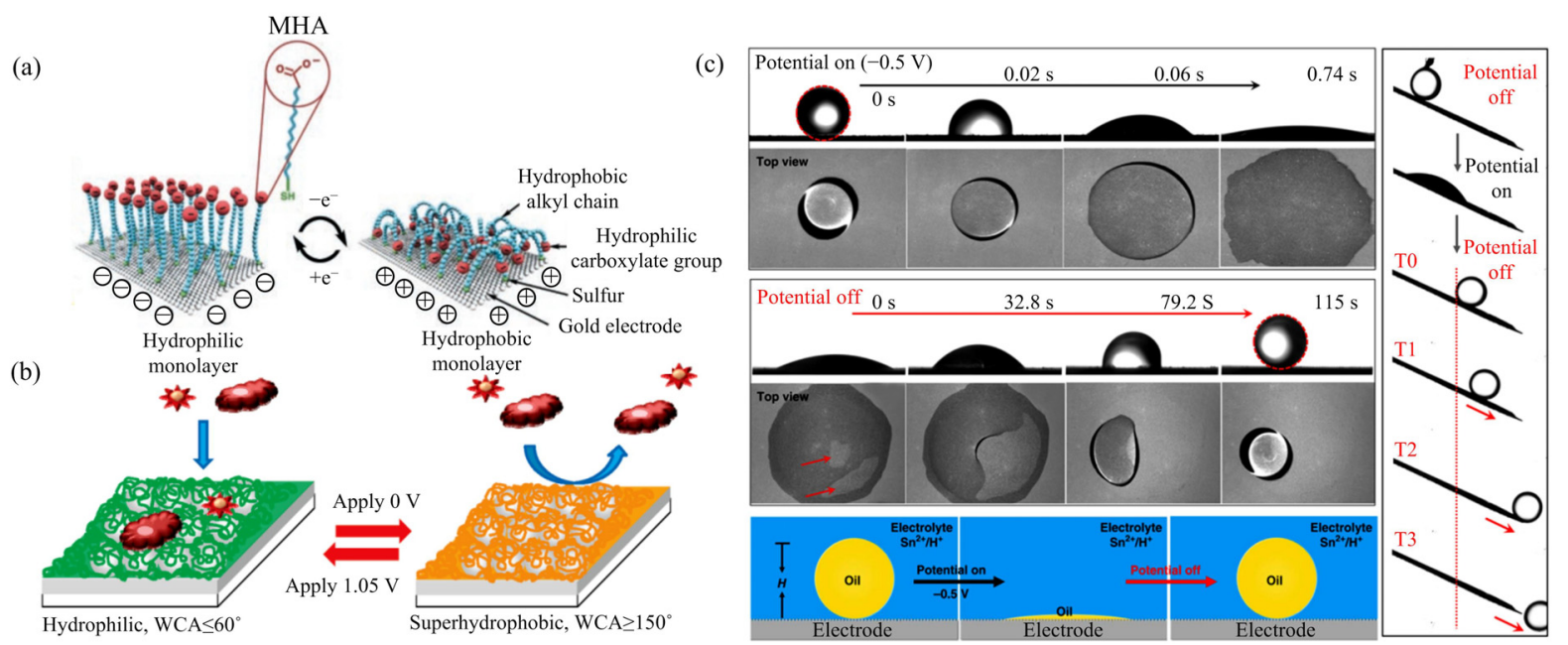

(d)

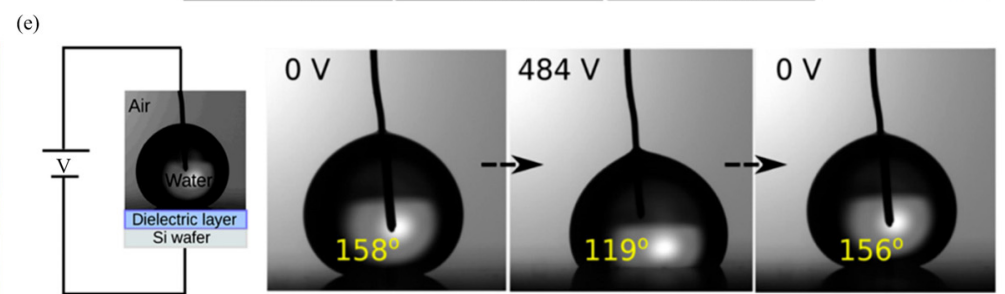

Fig. 6 (a) The transition mechanism between straight (hydrophilic) and bent (hydrophobic) molecular conformations of MHA ${ }^{[73]}$. (b) Protein and bacterial adhesion and wettability onto the undoped (orange-colored film) and doped (green-colored film) colloidally templated polythiophene film ${ }^{[70]}$. (c) The in situ reversible superwetting transition between underwater superhydrophilic and superoleophobic properties by electrochemical atomic alternation ${ }^{[74]}$. (d) Appling the voltage between the droplet and the substrate, different wetting states on the nanostructured substrate ${ }^{[77]}$. (e) The contact angle reversibility under the on/off voltage of $484 \mathrm{~V}^{[78]}$.

superhydrophobic surface with a dense array of magnetorheological elastomer micropillars (MREMPs) ${ }^{[87]}$. As shown in Fig. 7a, by tuning magnetic fields, the microstructures of MREMPs transformed from the collapsed state to the fully upright position, resulting in the surface adhesion changing from adhesive state to rolling state. Relying on the distribution of the magnetic nanoparticles inside the pillars, Drotlef et al. designed the arrays of actuated magnetic micropillars, which can be tilted, twisted, and rotated by varying the strength and the direction of the magnetic field gradient (Fig. 7b) ${ }^{[88]}$. At the same time, because the magnetically induced transformation of pattern geometry, the rolling angle of water droplets on the surface exhibited the magnetically direction-dependent wetting changes, which also can be used to obtain the transfer of microparticles. As shown in Fig. 7c, Huang et al. designed and fabricated a transformable surface consisting of an array of magnetic-responsive hierarchical micropillars ${ }^{[89]}$. By transforming the surface morphologies under an external magnetic field, the dynamically switchable wettability between the superhydrophobic and slippery states can be easily obtained.

\subsubsection{Mechanical stress}

Compared with the above stimuli, applying mechanical stress to achieve reversible controlment of surface wettability has the characteristics of faster, significant, continuous, and environmentally friendly ${ }^{[90]}$. Similarly, the regulation mechanism of surface wettability is the same as magnetic-induced transition, which is tuned by manipulating the microstructures.

Recently, as a kind of smart material, Shape Memory Polymers (SMPs) can recover their original shape after deformation by external stimulus ${ }^{[25]}$. On the basis of the shape memory effect of diglycidyl ether of bisphenol A (DGEBA) epoxy resin, Cheng's group demonstrated the intelligent regulation of epoxy SMP micro-nano array surfaces in rewritable microfluidic chips, anisotropic wettability, interfacial solid-liquid adhesion properties and repairable superhydrophobic surfaces ${ }^{[91-94]}$. As shown in Fig. 8a, under external force, 

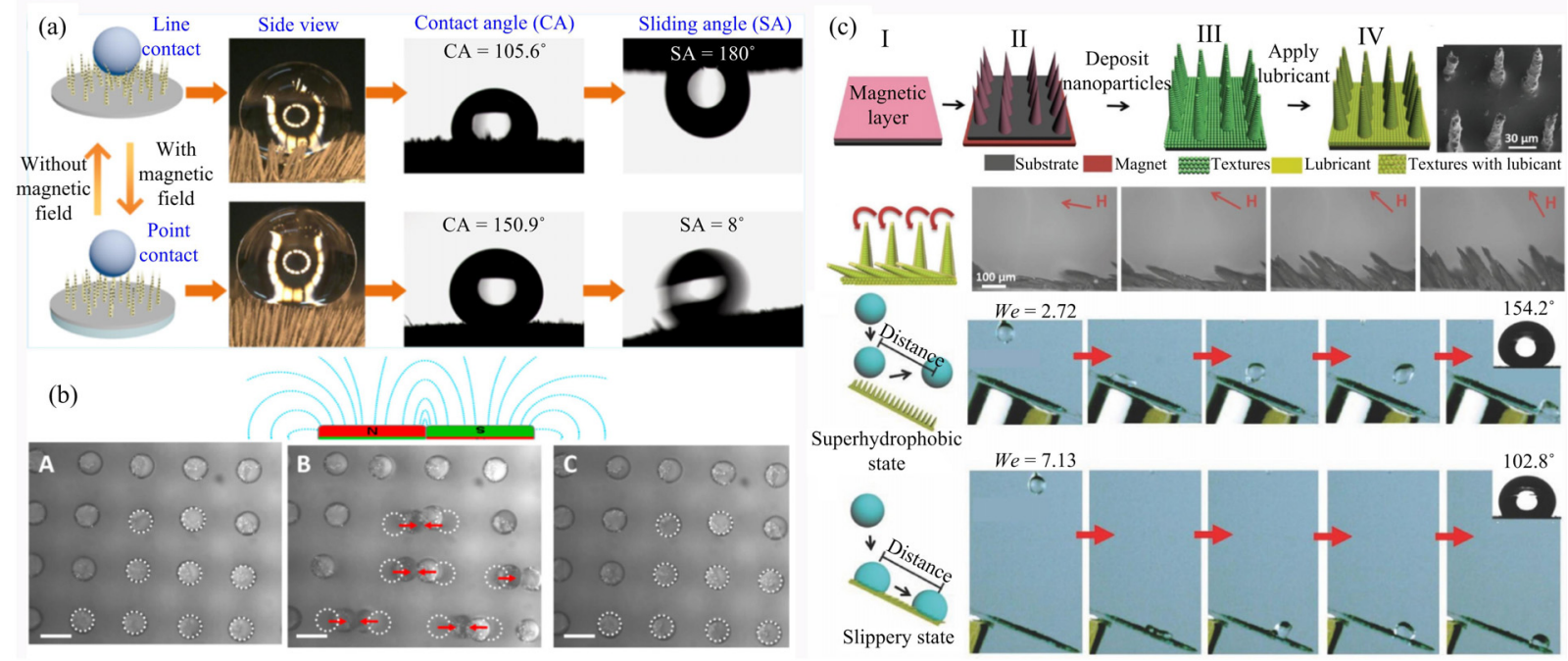

Fig. 7 (a) Switchable wettability and adhesion induced by the morphology of MREMPs under the on/off switching of magnetic field ${ }^{[87]}$. (b) The movement of micropillars in opposite directions with a magnetic gradient ${ }^{[88]}$. (c) Surface transformation between superhydrophobic and slippery states under directional magnetic field $\left.{ }^{[89}\right]$.

the surface microstructures on the epoxy SMP collapsed, showing high adhesion. However, the heat treatment can make the surface microstructure and adhesion properties restore to initial state owing to the shape memory characteristics, thereby realizing the reversible conversion of water droplets between low adhesion and high adhesion on the surface. In addition, the transformation between the lotus-leaf-like random state and the rice-leaf-like $1 \mathrm{D}$ ordered state was also realized due to the presence/absence of the microgroove structures by alternating mechanical stress and heating treatment, resulting in the superhydrophobic switching between the isotropic and anisotropic wettings.

In addition, several flexible materials also can be used for the transformation of the wetting state through structural changes. As shown in Fig 8b, Wang et al. fabricated a smart skin-like PDMS elastomer surface with dynamic wetting behaviors by laser direct writing technology ${ }^{[95]}$. The surface topography can be finely regulated by tuning the direction and strength of the exerted force, leading to the superhydrophobic wettability switch quickly between the "lotus effect" and "rose effect". Based on the transformation mechanism, they also applied the smart artificial skin to the joints of fingers, realizing the capture and release of water droplets only by finger motions without external energy supply or appliance. Similarly, by changing the surface microstructure under mechanical stress, Wu et al. de- signed an elastic regular array of pillars on PDMS substrate by using two-beam laser interference lithography and imprint lithography ${ }^{[96]}$. The adhesion force and sliding angle of treated PDMS substrate exhibited strong dependence on the surface curvature, which can achieve in situ switching wettability between pinned and roll-down superhydrophobic states, thus realizing the no-loss water droplet transportation.

\subsection{Chemical stimulation}

\section{$3.2 .1 \mathrm{pH}$}

As $\mathrm{pH}$ is one of the most common and easiest stimuli to regulate environmental response signals, $\mathrm{pH}$-responsive substances nowadays have been utilized in various fields, such as drug delivery, separation and biosensors. Plenty of compounds, mainly containing carboxyl, pyridine and tertiary amine groups, can be used to respond acidic or alkali aqueous through protonation and deprotonation of functional groups, such as poly(acrylic acid) (PAA) and poly(methacrylic acid) (PMAA), poly(vinylpyridine) (PVP), poly(dimethylamino) ethyl methacrylate (PDMAEMA), and $\mathrm{HS}\left(\mathrm{CH}_{2}\right)_{10} \mathrm{COOH}$ etc ${ }^{[97-102]}$.

Pyridine, an acid induced swollen group, can be protonated under acidic aqueous, which is often used for the transformation of $\mathrm{pH}$-responsive reversible wettability. By modifying the Porous Anodic Aluminum Oxide (PAAO) membrane with the $\mathrm{pH}$-responsive 

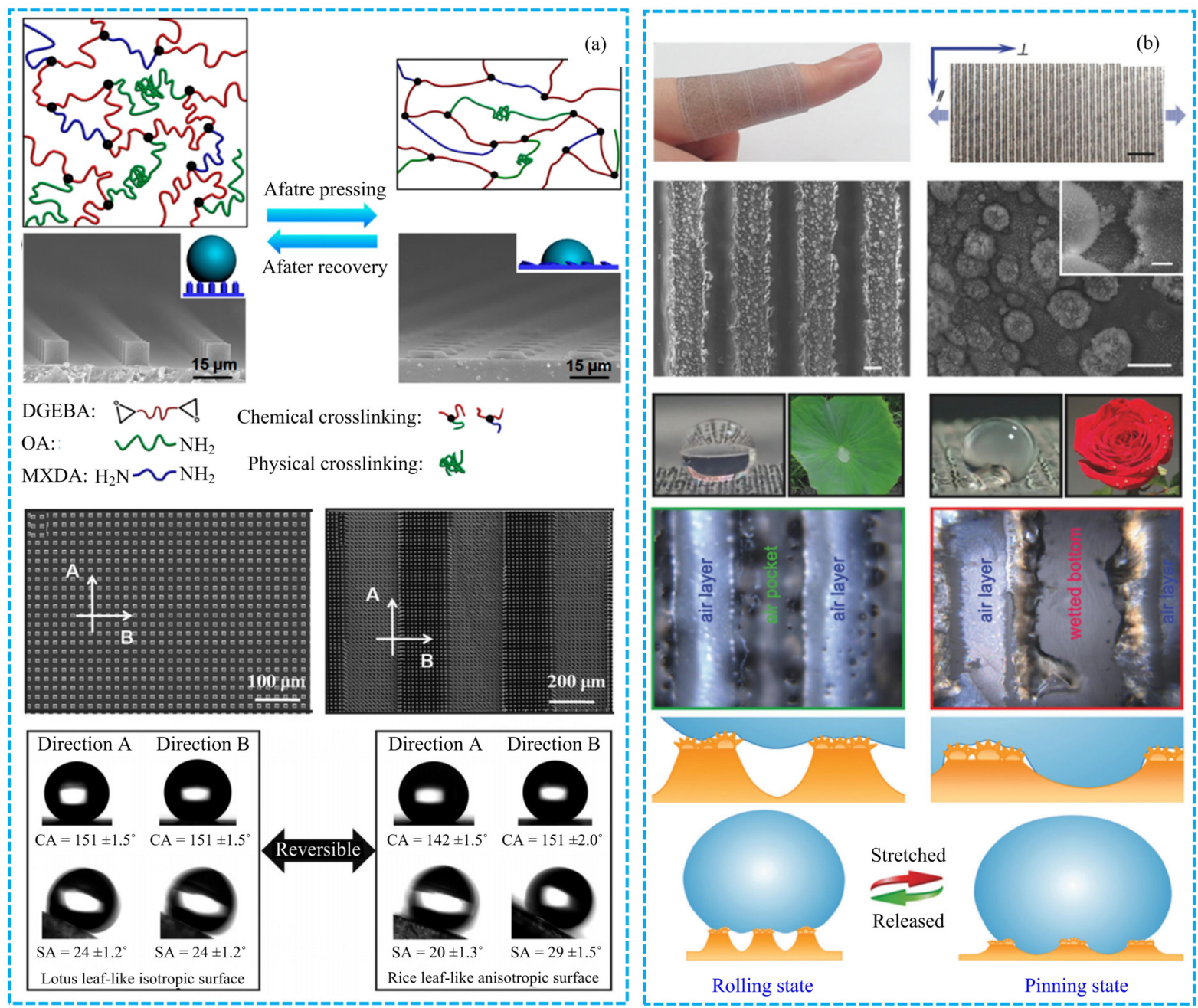

Fig. 8 (a) Schematic illustration of molecular chain conformation and wetting models of SMPs with/without pressing ${ }^{[93]}$. Surface microstructure variation between the lotus-leaf-like and rice-leaf-like structure shapes and the corresponding wetting results, concluding the $\mathrm{CA}$ and SA. Directions A and B are the measured directions as labeled in images ${ }^{[94]}$. (b)Wearable structured surface with periodic gratings and different wetting state with or without stretching $\operatorname{strain}^{[95]}$.

poly(4-vinylpyridine) (P4VP) and hydrophobic/oleophilic polystyrene block copolymer, Cai et al. fabricated a smart surface on a PAAO membrane with the characteristic of antifouling and $\mathrm{pH}$-responsive oil wettability (Fig. 9a) ${ }^{[103]}$. While immersed in acidic water, P4VP chains protonated and exposed, resulting in the hydrophilicity and superoleophobicity. However, the membrane transformed into initial superoleophilicity quickly while move into the neutral water and drying. In contrast to the acid induced swollen pyridine group, carboxylic group, an alkali induced swollen group, possess the similar $\mathrm{pH}$-induced wettability. While the $\mathrm{pH}$ is lower (or higher) than its $\mathrm{pKa}$ (around 5-6), the carboxyl groups will be protonated (or deprotonated), resulting in hydrophobicity (or hydrophilicity).
Through grafting acrylic acid (AA) and acrylamide (AM) onto the eucalyptus pulp cellulose via $\mathrm{Ce}$ (IV)-initiated free-radical polymerization, Cheng et al. fabricated a smart $\mathrm{pH}$-responsive surface with reversible wettability (Fig. 9b) ${ }^{[102]}$. Due to the presence of oppositely charged groups in terms of pH-responsivity, as the $\mathrm{pH}$ values switched between 1 and 9, the amino or carbonyl group on the compound surface undergone protonation or deprotonation, causing switchable wettability between oleophobic-hydrophilic and hydrophobic-oleophilic, so as to achieve the controlled oil-water separation.

Nevertheless, it can be found that $\mathrm{pH}$-responsive copolymers often require relative longer time to achieve the wettability transition. In comparison with the ordinary 


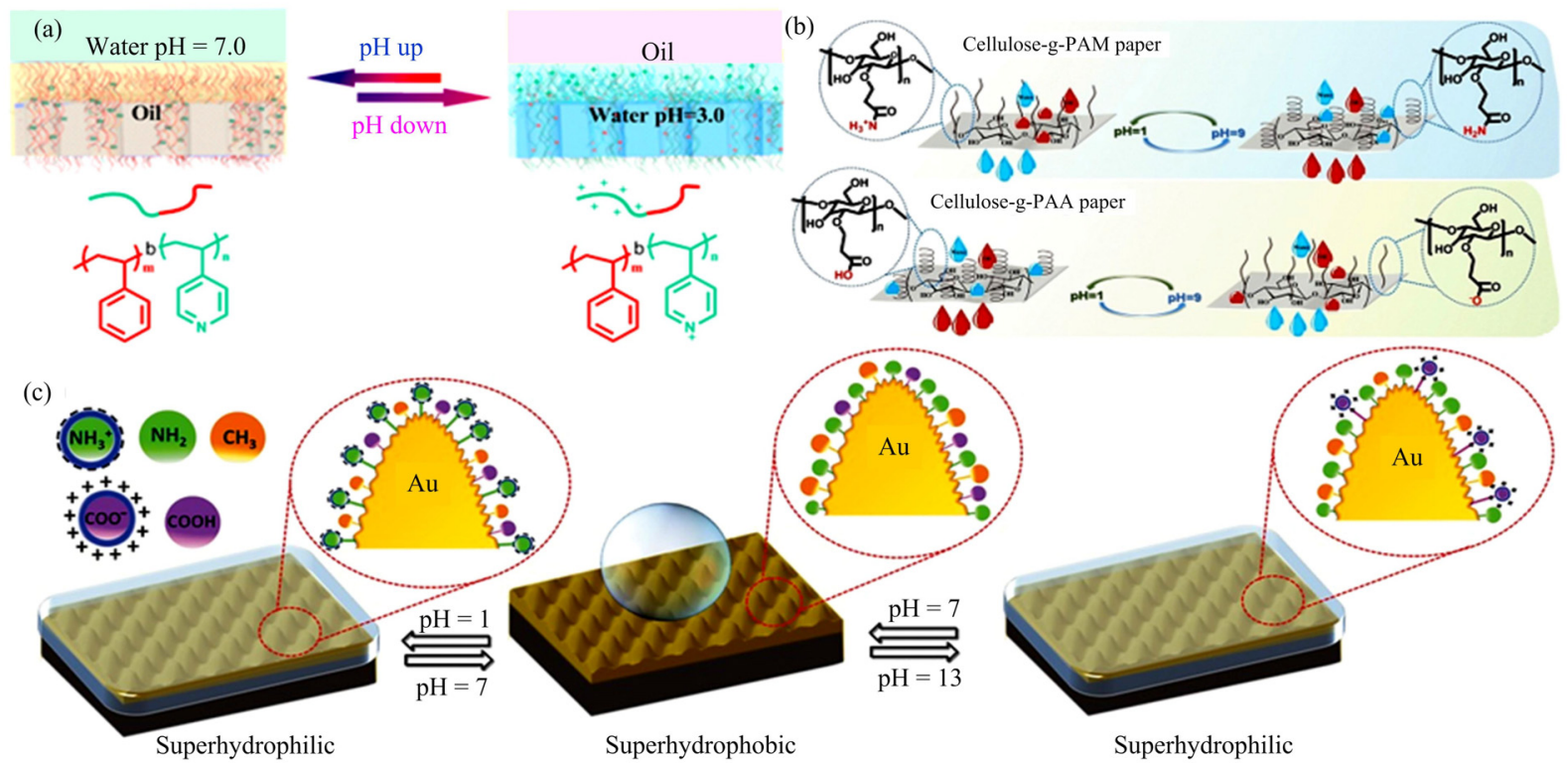

Fig. 9 The pH-responsive mechanism of reversible wettability of the surface grafted with different compounds. (a) Acid-induced swollen pyridine group, schematic illustration of the switchable oil wettability of the PS-b-P4VP-grafted PAAO membrane under acidic aqueous ${ }^{[103]}$. (b) The carboxylic group in PAA and amino groups in PAM under different $\mathrm{pH}$, the cellulose-g-PAA and cellulose-g-PAM paper with opposite switchable oil/water wettability ${ }^{[102]}$. (c) Illustration of the various surface modified by the mixed thiols under different pH conditions ${ }^{[99]}$.

free radical polymerizations, modification with thiol molecules (such as $\mathrm{HS}\left(\mathrm{CH}_{2}\right)_{11} \mathrm{OH}, \mathrm{HS}\left(\mathrm{CH}_{2}\right)_{9} \mathrm{CH}_{3}$, $\left.\mathrm{HS}\left(\mathrm{CH}_{2}\right)_{10} \mathrm{COOH}\right)$ is more likely to reduce the complicated synthesis process of smart separation materials (Fig. 9c) ${ }^{[99]}$. For example, combined the porous nylon membrane with self-assembled thiol molecules, Li et al. fabricated a smart membrane with tunable wettability property upon the $\mathrm{pH}$ variation, effectively separating various oil/water mixtures and surfactant-stabilized emulsions with excellent recyclability of the long-term separation ${ }^{[104]}$. Similarly, through the grafting of $\mathrm{HS}\left(\mathrm{CH}_{2}\right)_{11} \mathrm{CH}_{3}$ and $\mathrm{HS}\left(\mathrm{CH}_{2}\right)_{10} \mathrm{COOH}$, Liu et al. fabricated $\mathrm{pH}$-responsive super-wettable surfaces on the metal substrate, such as copper foams, aluminum alloy and copper alloy ${ }^{[105-107]}$. The switchable surface wettability induced by $\mathrm{pH}$-triggered protonation and deprotonation processes, endowed the as-prepared specimens with the properties of continuously separating the oil/water mixtures, or manipulating or storing types of microdroplets. Even though the $\mathrm{pH}$-responsive surfaces with rapid wettability transformation is critical in potential applications, there are still several obstacles to be resolved, such as the $\mathrm{pH}$ sensitivity enhancement, large variation in wettability and eco-friendly etc., which limits its application to some extent.

\subsubsection{Ion}

Designing ion-responsive surfaces open up a new strategy to tune wettability dynamically, which is induced by ion-pairing interactions between cationic or anionic electrolytes and their complexes ${ }^{[108-110]}$. Based on the characteristic of reversible counterion exchange, series of materials consisting of amine or nitrogen heterocycles with a quaternized moiety, such as polypyrrole, quarterized amine polymers, ionic liquid-based polymers or quaternary ammonium thiolated molecules etc., are used for the control of wettability ${ }^{[111-113]}$. Via self-assembly method, Osicka et al. ${ }^{[114]}$ fabricated rough-structured gold surface with Self-Assembled Monolayer (SAM) on a silicon wafer, consisting of positively charged quaternary ammonium group with aliphatic tail bearing terminal thiol functionality. This work achieved the switchable wettability from superhydrophilic and superhydrophobic state by counterion exchange from $\mathrm{Cl}-$ to perfluorooctanoate ( $\mathrm{PFO}-$ ) firstly. Combined with the kinetics of counterion exchange, the changes in wettability are ascribed for a long hydration process and strong electron ion pairing between qua- 
ternary ammonium group and perfluorooctanoate counterion. On account of the salt-responsive property of zwitterionic polymer brushes, Zheng's teamwork developed poly(3-(1-(4-vinylbenzyl)-1H-imidazol-3-ium3 -yl) propane-1-sulfonate) (poly VBIPS) to switch surface wettability from $40^{\circ}$ to $25^{\circ}$, while exposed to Phosphate Buffer Saline (PBS) in water or sodium chloride solution ${ }^{[115,116]}$. The salt-responsive behaviors can be explained by the effects of ionic strengths on the chain conformation of poly VBIPS brushes. While in the PBS/water, the polymers' chain conformation collapsed to realize surface adhesion, but with an extended state in $\mathrm{NaCl}$ solution to obtain antifouling property, thereby switching the protein capture/release reversibly in the biomedical application.

In addition, metal-ion-induced in dynamically wettability transition always have been reported. By grafting the liner poly(acrylic acid) (PAA) onto the polydopamine-coated stainless-steel mesh, $\mathrm{Xu}$ et al. developed a new method for achieving the wettability transition on basis of the chelation between $\mathrm{Hg}^{2+}$ and PAA $^{[117]}$. The as-prepared superhydrophilic mesh transformed into a highly hydrophobic with a contact value about $149^{\circ}$ after immersed in $\mathrm{Hg}^{2+}$ solution, which can be used as an ideal material for the $\mathrm{Hg}^{2+}$ detection and oil-polluted water purification. Via one-step immersion in salt solution $\left(\mathrm{FeCl}_{3}\right)$, the $\mathrm{N}$ atoms in the intrinsically hydrophilic melamine sponge coordinated with the transition metal ions $\left(\mathrm{Fe}^{3+}\right)$, and a highly hydrophobic and oleophilic sponge was prepared by Ding et al. ${ }^{[118]}$.

\subsubsection{Solvent}

The influence of the surrounding media on the wettability is mainly reflected in the sensitivity of the smart surface to the solvent ${ }^{[119-122]}$. Among the reported solvent-responsive polymers, the reason for the transition in switchable wettability is caused by the change of interfacial free energy owing to the configurational changes in polymer chains ${ }^{[123,124]}$. Liu et al. fabricated a Janus actuator with superhydrophobic and hydrophobic sides with the mixtures of PDMS and graphene via laser etching, realizing on-off switchable ability between an oil/water mixture and ethanol due to the changes of surface tension and absorption expansion ${ }^{[125]}$. Diffe- rently, by adding sugar or diluting to water, Yong et al. realized the no-loss oil droplet transportation on the femtosecond laser-irradiated silicon surfaces in a water environment ${ }^{[126]}$. When adding sugar, the density of water solution surrounding oil droplet increased, as well as the buoyancy acting on the oil droplet was larger than the gravity, causing an oil droplet to be picked up. While diluting the water, the oil droplet was put down. By changing the density of the solution (larger or lower than that of the oil), this surface is used to achieve the transport of oil droplets as an in situ "mechanical hand". However, compared with the above stimuli-responsive smart surfaces, most of the solvent-responsive surfaces with switchable wettability are often only sensitive to one or a few specific solvents, greatly limiting their applications.

Finally, in order to compare relevant studies parallelly, summative words for the above works are further listed in Table 1. It mainly includes the corresponding responsive materials used for the preparation of smart reversible surfaces, the achieved wetting performances, features in surface control, the advantages and disadvantages of surface wetting control.

\subsection{Dual/Multi-stimuli}

Recently, dual and multiple responsive surfaces with switchable wettability have been developed to respond to multiple triggers simultaneously or independently. This will provide a more effective strategy for functional control from different directions and satisfy basic research and industrial applications ${ }^{[127-131]}$. Based on as-prepared hydrogels in response to stretch, $\mathrm{pH}$ and temperature, Huang et al. ${ }^{[132]}$ built a system with controllable wettability responding to multiple types of stimuli simultaneously (Fig. 10a). The wettability transition was consistent with the hydrogel state in constriction or expansion. And that, a container made by different composite materials contained a dye of different color, was used to directly demonstrate the specific changes in wettability. Beyond that, combined the tunable surface microstructure owing to the shape memory effect of SMPs and the temperature-responsive PNIPAAm with switchable hydrophilicity/hydrophobicity, Zhang et al. ${ }^{[133]}$ also designed various smart gradient wetting surface with responsivity in both 
Table 1 Summary of smart surface with switchable wettability

\begin{tabular}{|c|c|c|c|c|c|c|}
\hline $\begin{array}{l}\text { Responsive mate- } \\
\text { rials }\end{array}$ & Stimuli & $\begin{array}{l}\text { Reversible wetting per- } \\
\text { formances }\end{array}$ & $\begin{array}{c}\text { Features in } \\
\text { surface control }\end{array}$ & Advantages & Disadvantages & References \\
\hline $\begin{array}{l}\text { Thermosensitive } \\
\text { polymer }\end{array}$ & $\begin{array}{l}\text { Tem- } \\
\text { perature }\end{array}$ & $\begin{array}{l}\text { Hydrophilicity and under- } \\
\text { water superoleophobicity } \\
\text { /hydrophobicity and supe- } \\
\text { roleophilicity transition }\end{array}$ & $\begin{array}{l}\text { Surface com- } \\
\text { position }\end{array}$ & $\begin{array}{l}\text { Facile operation, without } \\
\text { chemical addition }\end{array}$ & $\begin{array}{l}\text { Longer respon- } \\
\text { sive time }\end{array}$ & {$[49]$} \\
\hline $\begin{array}{l}\text { Inorganic semicon- } \\
\text { ductor oxides, or- } \\
\text { ganic light-sensitive } \\
\text { polymers }\end{array}$ & Light & $\begin{array}{l}\text { Hydrophobicity and super- } \\
\text { hydrophilicity transition }\end{array}$ & $\begin{array}{l}\text { Surface com- } \\
\text { position }\end{array}$ & $\begin{array}{l}\text { Rapid, facile operation, } \\
\text { remote control }\end{array}$ & $\begin{array}{l}\text { Specific wave- } \\
\text { length }\end{array}$ & {$[29,61]$} \\
\hline $\begin{array}{l}\text { Conductive poly- } \\
\text { mers or substrate }\end{array}$ & Electric & $\begin{array}{l}\text { Hydrophilicity and super- } \\
\text { hydrophobicity transition }\end{array}$ & Surface energy & $\begin{array}{l}\text { Super-fast responsiveness, } \\
\text { convenient controlment }\end{array}$ & $\begin{array}{l}\text { Low safety } \\
\text { factor, complex } \\
\text { fabrication }\end{array}$ & $\begin{array}{c}{[70,73,77,} \\
78]\end{array}$ \\
\hline $\begin{array}{l}\text { Magnetic par- } \\
\text { ticles/fluids }\end{array}$ & $\begin{array}{l}\text { Mag- } \\
\text { netic }\end{array}$ & Dynamic wetting transition & $\begin{array}{l}\text { Surface micro- } \\
\text { structure }\end{array}$ & $\begin{array}{l}\text { Safety, fast responsiveness, } \\
\text { easy to operate, low energy } \\
\text { consumption, eco-friendly }\end{array}$ & $\begin{array}{l}\text { Magnetic } \\
\text { material assis- } \\
\text { tance }\end{array}$ & [87-89] \\
\hline $\begin{array}{l}\text { SMPs, flexible } \\
\text { material }\end{array}$ & $\begin{array}{l}\text { Me- } \\
\text { chanical } \\
\text { stress }\end{array}$ & Dynamic wetting transition & $\begin{array}{l}\text { Surface micro- } \\
\text { structure }\end{array}$ & $\begin{array}{l}\text { Fast responsiveness, conti- } \\
\text { nuous, eco-friendly }\end{array}$ & $\begin{array}{l}\text { Contact reac- } \\
\text { tion }\end{array}$ & [93-95] \\
\hline $\begin{array}{l}\text { Pyridine, carboxyl, } \\
\text { and tertiary amine } \\
\text { groups }\end{array}$ & $\mathrm{pH}$ & $\begin{array}{l}\text { Superoleophilicity and } \\
\text { hydrophilicity/ superoleo- } \\
\text { phobicity transition }\end{array}$ & $\begin{array}{l}\text { Chemical } \\
\text { composition }\end{array}$ & $\begin{array}{l}\text { Easy operation, wide ap- } \\
\text { plication }\end{array}$ & $\begin{array}{l}\text { Long respon- } \\
\text { sive time, low } \\
\text { sensitivity, } \\
\text { heavy metal or } \\
\text { complex prep- } \\
\text { aration }\end{array}$ & $\begin{array}{l}{[99,102} \\
103]\end{array}$ \\
\hline $\begin{array}{l}\text { Metal-ion, amine or } \\
\text { nitrogen hetero- } \\
\text { cycles with quater- } \\
\text { nized moiety }\end{array}$ & Ion & $\begin{array}{l}\text { Superhydrophilicity and } \\
\text { hydrophobicity transition }\end{array}$ & $\begin{array}{l}\text { Chemical } \\
\text { composition }\end{array}$ & Easy to operate & $\begin{array}{l}\text { Specific reac- } \\
\text { tion }\end{array}$ & {$[114,117]$} \\
\hline Surrounding media & Solvent & $\begin{array}{l}\text { Superhydrophilicity and } \\
\text { hydrophobicity transition }\end{array}$ & $\begin{array}{l}\text { Interfacial free } \\
\text { energy }\end{array}$ & Easy to operate & $\begin{array}{l}\text { Only sensitive } \\
\text { to one or a few } \\
\text { specific sol- } \\
\text { vents }\end{array}$ & [126] \\
\hline
\end{tabular}

surface microstructure and chemistry for the first time (Fig. 10b). Moreover, the authors designed a rewritable platform for repeatedly creating different gradient wettings with four parts, i.e. upright pillars with hydrophobicity, collapsed pillars with hydrophobicity, collapsed pillars with hydrophilicity and upright pillars with hydrophilicity. Based on this route, it was demonstrated that the surface possessed an excellently tunable wettability, which may expand to other wetting-dependent functional applications.

\section{Applications of smart wettability}

Recently, smart materials with special controllable wetting surfaces have attracted an increasingly attention in many fields. Especially, lots of relevant researches mostly have centered upon oil/water separation, programmable transportation, anti-biofouling, detection and delivery, smart soft robotic and others.

\subsection{Oil-water separation}

Oil-water separation is a hot topic in the industry field and daily life due to the oil leakage, increasing oily industrial wastewater and so on ${ }^{[108,134,135]}$. Recently, materials with special interfacial superwettability have proven to be highly efficient to solve the practical problem, such as membrane-based separation materials, porous sponge-based absorption materials, metal/covalent-organic framework meshes, porous carbon materials, fabrics, and coatings etc ${ }^{[136-140]}$. Comparatively, the smart materials with switchable wettability by external excitation also can be used for complex environments and mixed solvents with high flux and high selectivity, which is favor to separate the oil/water mixtures on-demand, efficiently and energy-savingly ${ }^{[141-143]}$.

The reversible wettability between superhydrophobicity/underwater superlipophilicity and superhydrophilicity/underwater superoleophobicity has received extensive attention. The smart surface with switchable wettability selectively presents two processes between "oil-removing" and "water-removing"[144]. While the surface is superhydrophobic/superoleophilic in air, the 
(a)

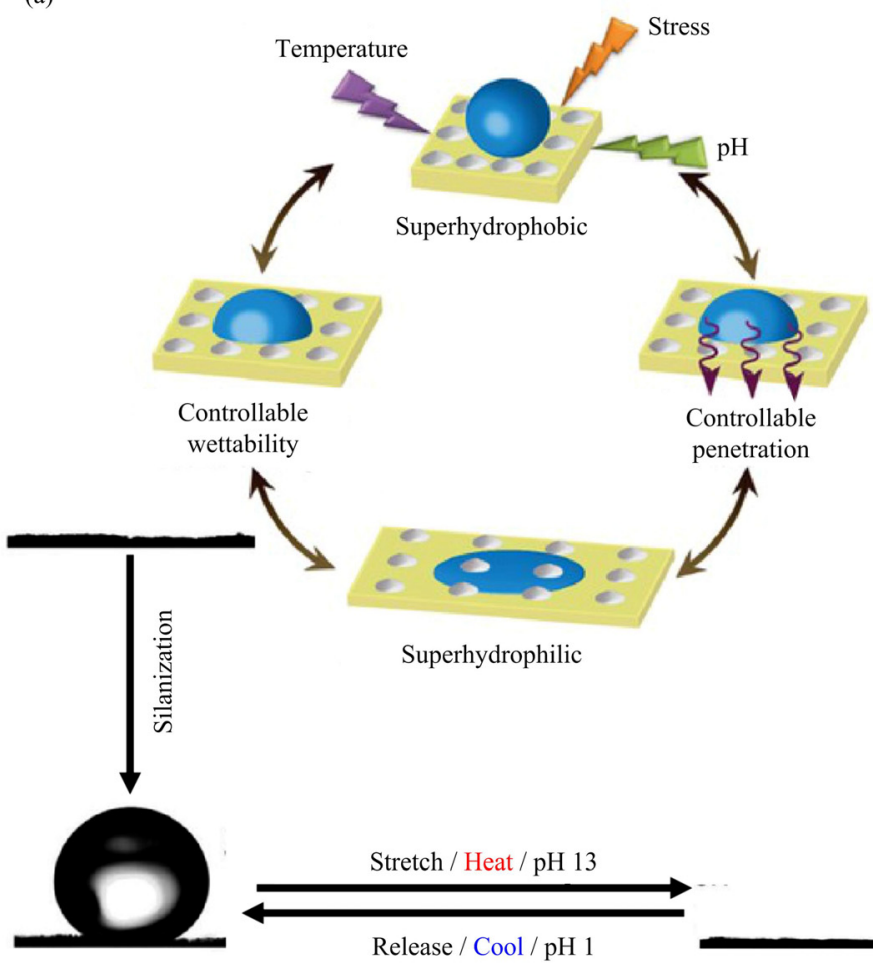

(b)
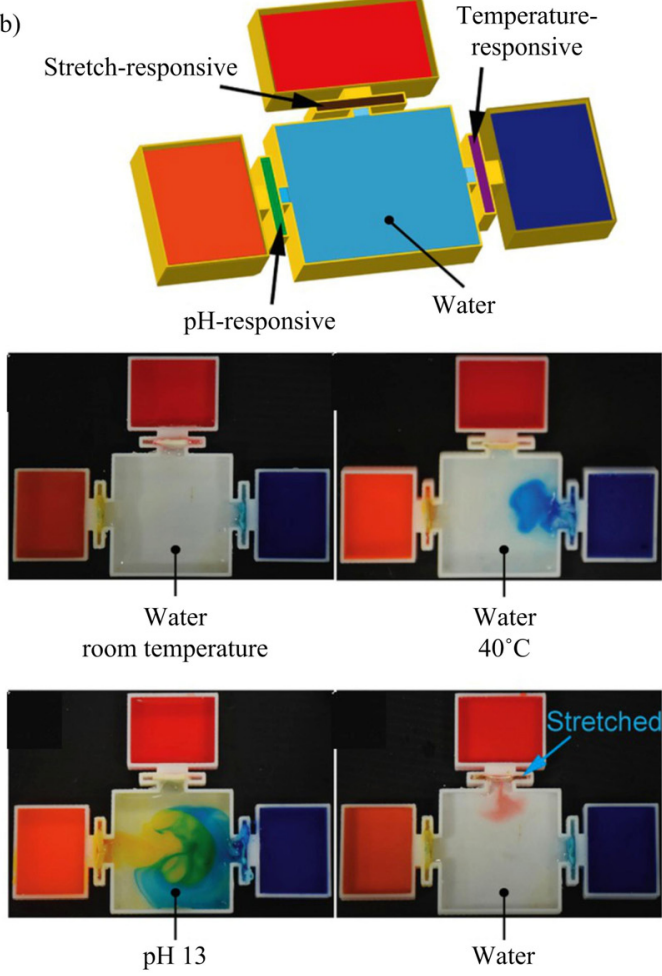

room temperature

room temperature

(d)
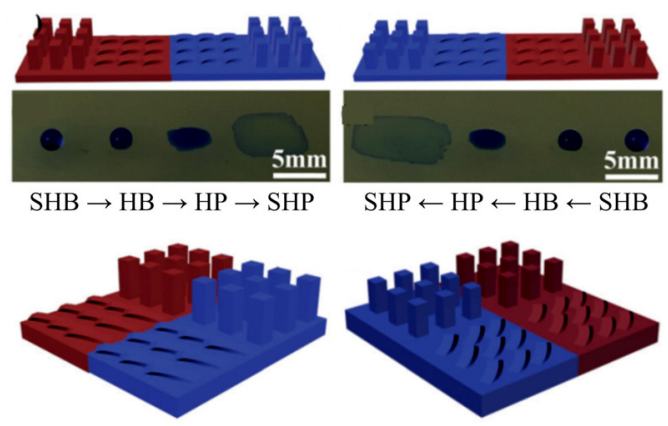

After pressing
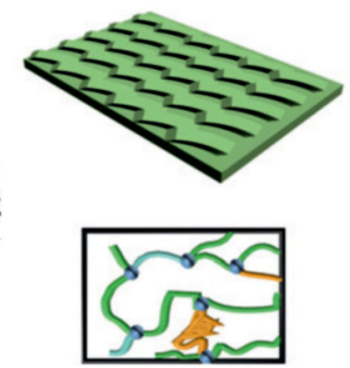

Shape memory polymer
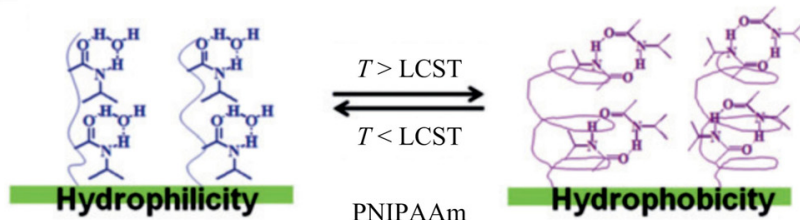
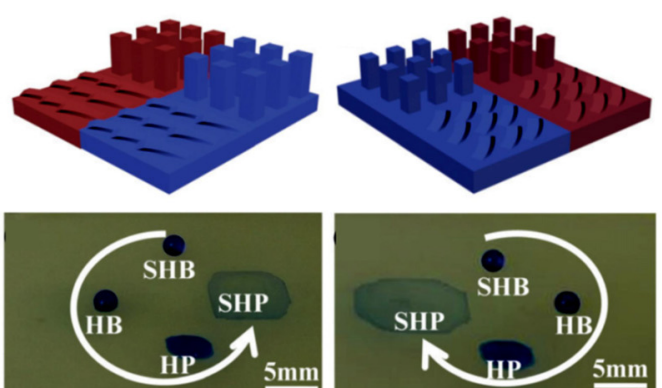

SHB: superhydrobicity HB: hydrophobicity HP: hydrophilicity SHP: superhydrophilicity Red region: $T=50^{\circ} \mathrm{C}$ Blue region: $T=20^{\circ} \mathrm{C}$

Fig. 10 (a) Controlling the wettability by the stress/temperature/pH-responsive composite material, and presenting a multiple responsive system and wetting changes by the outside contain dyes of different colors. While stretched the stretch-responsive material, the red dye will diffuse into the center. Similarly, the $40{ }^{\circ} \mathrm{C}$ water induced the blue dye diffusing into the center, and a basic solution of $\mathrm{pH} 13$ aroused the orange dye and blue dye diffusing into the center due to the exertion of stimuli ${ }^{[132]}$. (b) Surface fabrication by combining shape memory effect of SMPs and temperature-responsive PNIPAAm, applying as a rewritable platform for creating different gradient wettings by controlling surface microstructure and chemistry simultaneously ${ }^{[133]}$.

heavy oil can pass through the film while retaining the water, working in an oil removing mode. While the surface is superhydrophilic/underwater superoleophobic, the water could spontaneously permeate through while preventing light oil from passing, belonging to the water removing mode. Based on the $\mathrm{pH}$-responsive materials of thiol molecules, smart copper foams with reversible wettability between superhydrophobicity and hydrophi- 
licity were used for the separation of oil/water mixtures with high efficiency in the neutral solution or basic solution bidirectionally in our previous work ${ }^{[105]}$. As shown in Fig. 11, while the $\mathrm{pH}$ increased, the surface wettability transformed into superhydrophilicity and underwater superoleophobicity, the "water-removing" mode allowed the water in the oil-water mixture to pass through the foam and into the beaker below. Nevertheless, while the $\mathrm{pH}$ decreased, as for the mixtures of dichloroethane and water, there appeared a opposite separation phenomenon of oil permeability.

\subsection{Programmable transportation}

In addition to the control of static wetting, the surface wettability transition also exhibits in the dynamic wettability by the droplet sliding property. Programmable droplet transportation is usually caused by changes in dynamic wettability under external stimuli, showing the difference in contact angle and anisotropic wetting behavior in two directions, which can be applied in various fields, such as biomedicine for non-powered micro-drug delivery, controllable self-lubricating transfer in mechanical engineering, controllable microfluidics system and long-distance water delivery for agricultural drip irrigation $e t c^{[145-148]}$. Inspired by the microstructure of stomata distributed on plants, Zhao et al. prepared a surface with programmable wettability arrays by using microfluidic emulsification templates, achieving the printing with mask integration because of the property of controllable droplet sliding on programmable wettability pathways and effective droplet transfer (Fig. 12b) ${ }^{[147]}$. Zhang et al. fabricated a temperature-adaptive V-shaped Prism Microstructures (VPM) surface to realize on-demand switchable direction transport of liquid in situ and real-time upon microarrays and thermal stimuli, which was unidirectional, bidirectional and directionally switchable transportation, so as to achieve precise liquid transport according to the path of the microfluidic channel (Fig. 12c) ${ }^{[149]}$. Inspired by the lotus and pitcher plants, $\mathrm{Li}$ and his teamwork fabricated a PDMS@ $\mathrm{Fe}_{3} \mathrm{O}_{4}$ fabric surface via one-pot method, realizing a switchable surface between the superhydrophobic state and slippery state under external magnetic field, which can achieve anisotropic water transmission and programmable fog harvesting $^{[150]}$.

\subsection{Anti-biofouling}

The phenomenon of biological adhesion and aggregation on the material surface has brought great harm to the actual life and production of human beings, which has caused a great impact on the medical, food, shipping and others ${ }^{[151-153]}$. The biofouling processes usually contain non-specific adsorption of biomolecules (lipids,

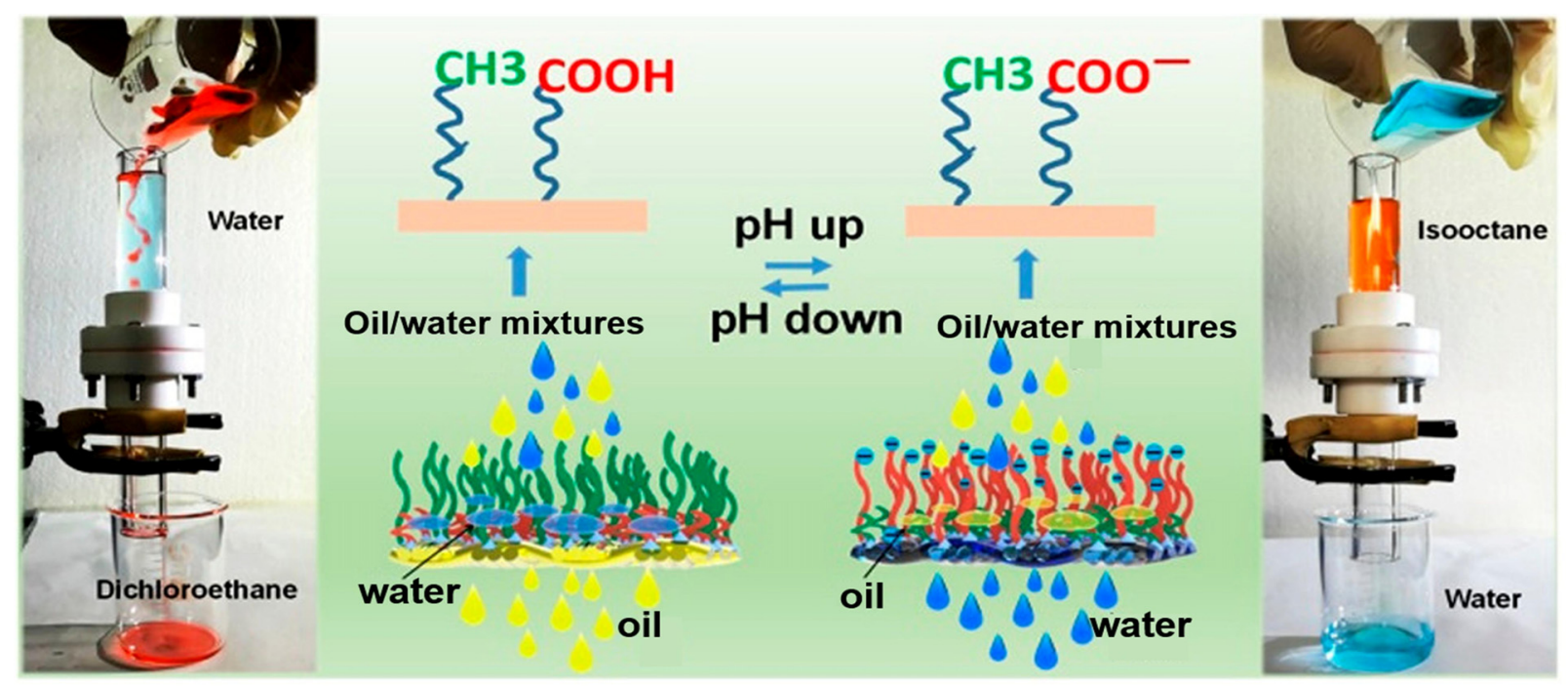

Fig. 11 Controllable oil/water separation mode for oil-water mixtures with different $\mathrm{pH}$ values. Left, oil-removing mode, while $\mathrm{pH}$ up, water passed through the foam, whereas oil remained in the upper glass tube; Right, water-removing mode, while pH down, oil passed through the foam while water remained on the top ${ }^{[101]}$. 


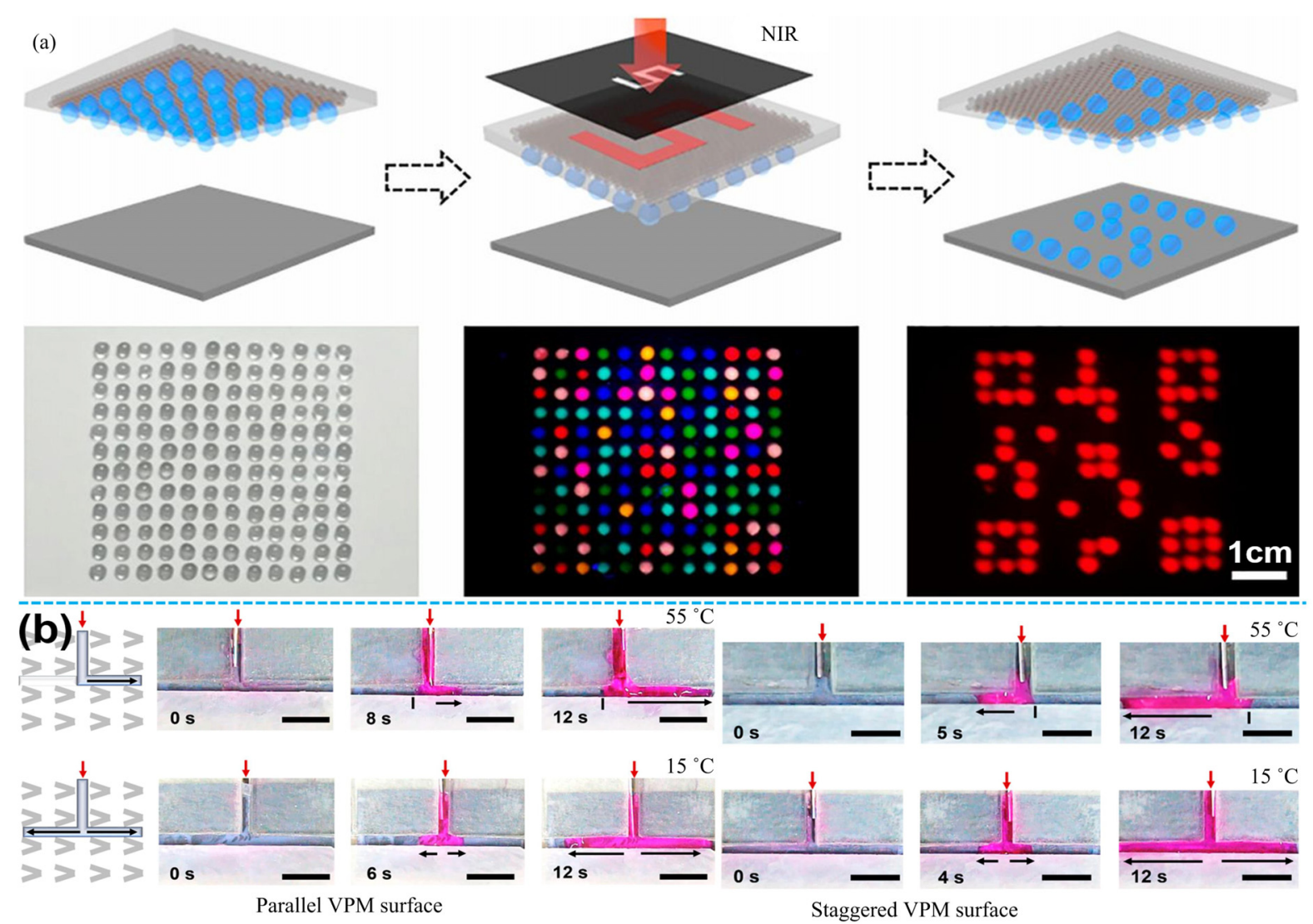

Fig. 12 (a) Schematic diagram of patterned droplets' release with photomask and droplet array of hidden $2 \mathrm{D}$ code information ${ }^{[147]}$. (b) On-demand directional liquid transport in microfluidic channels ${ }^{[149]}$.

glycans, proteins, etc.), molecular recognition-regulated cellular behaviors, and the formation of bacterium biofilms. According to this characteristic, smart materials interface with switchable wettability plays an important role in controlling the capture and release of cells, bacteria, and proteins ${ }^{[154-157]}$. Hou and coworkers developed a nanomaterial platform with controlling the capture and release of Circulating Tumor Cells (CTCs) by switching wettability between hydrophobic (at $37{ }^{\circ} \mathrm{C}$ ) and hydrophilic (at $4{ }^{\circ} \mathrm{C}$ ) upon grafting PNIPAAm onto surface (Figs. 13a and 13b ${ }^{[158]}$. Based on the thermo-responsive polymers, Li et al. obtained a smart surface for adsorbing or desorbing fibronectin via electrospinning technology, which is due to the surface wettability transformation caused by the structural changes under different temperature ${ }^{[159]}$.

Meanwhile, the smart wettability surfaces with capability of killing and releasing bacteria offer a new methodology for the practical applications in the biomedical and biotechnology fields. Yang et al. ${ }^{[160]}$ pre- sented a facile method for PNIPAAm functional surfaces by in situ preparation of silver nanoparticles (Ag NPs), which offered a "smart" antibacterial capability by controlling the surface wettability upon response to the change of environmental temperature. Large numbers of E. coli were killed at $37{ }^{\circ} \mathrm{C}$ and released at $4{ }^{\circ} \mathrm{C}$ on demand (Figs. 13c and 13d). Fu et al. fabricated smart antibacterial fabrics with the $\mathrm{pH}$-responsive switchable wettability via the cross-linking reaction of poly(ureaformaldehyde) (PUF) NPs contained methylol and hexamethylene diisocyanate ${ }^{[161]}$. Since the acid solution will affect the $\mathrm{N}^{+}$concentration on the surface, the surface wettability transformed rapidly under different $\mathrm{pH}$ solution. Due to the transition of surface wettability from superhydrophobicity to superhydrophilicity, the absorption rate of bacteria changed, leading to the change of bactericidal rate accordingly. As for the bactericidal rate, the values were $80.0 \%$ and $83.33 \%$ corresponding to solution of $\mathrm{pH}=7$ and $\mathrm{pH}=13$, whereas the sterilization rate slightly increased to 


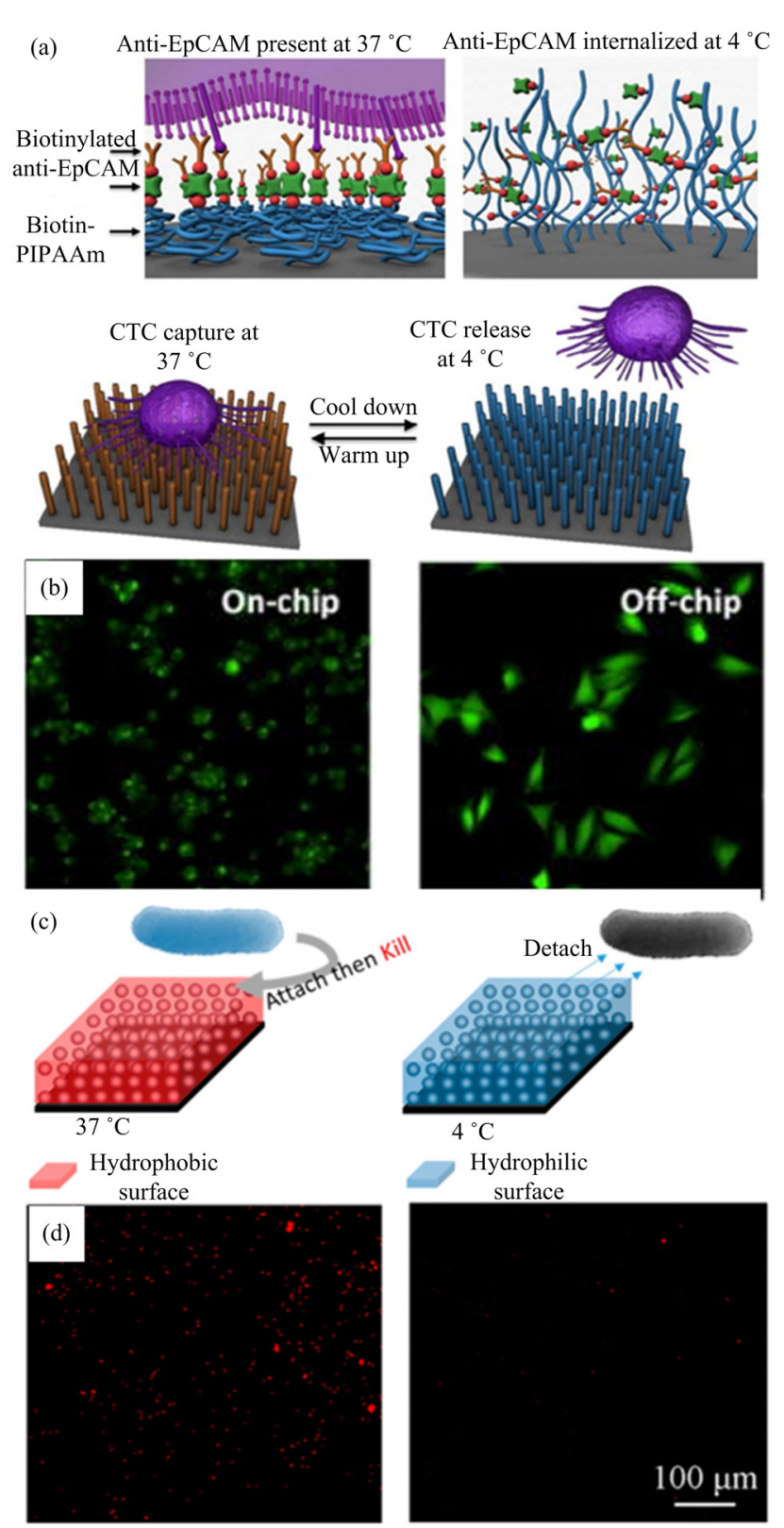

Fig. 13 (a) Conceptual illustration of a nanomaterial-based platform for cell-affinity assay capable of capturing CTCs with superb efficiency and releasing upon stimulation these captured CTCs under reduced temperature, and (b) the successful culture of CTCs after capture and released from prepared specimen ${ }^{[158]}$. (c) Schematic of bacterial attachment and detachment in response to temperature variation, and (d) the corresponding confocal microscope fluorescence graphs of $E$. coli ${ }^{[160]}$.

$88.67 \%$ under $\mathrm{pH}=1$.

\subsection{Detection and delivery}

The smart wettability surfaces also have applied in drug transportation and detection, which provides a new way for the development of convenient and fast detec- tion platforms and new drugs ${ }^{[162,163]}$. Liu et al. fabricated a Flexible Drug Release Device (FDRD) powered by a triboelectric nanogenerator (TENG), realizing the collection of biomechanical energy and converting it into electrical energy ${ }^{[164]}$. Induced by the electric effects by the on/off of mechanical switch, the wettability of the poly(3-hexylthiophene) P3HT layer in $\mathrm{Na}_{2} \mathrm{SO}_{4}$ aqueous solutions changed from hydrophobicity to hydrophilicity, so as to release the small molecules, such as methylene blue, fluorescein sodium and rhodamine $6 \mathrm{G}$ from the FDRD, realizing the controllable and continuable release of drug. Different from the traditional detecting techniques, visual assay in detection have attracted lots of researchers' attention, which is mainly dependent on the changes of wetting behaviors under stimuli, including the static and dynamic state ${ }^{[165]}$. In virtue of rapid pH-responsive switchable superwettability between superhydrophilic and superhydrophobic, Jiang's team implemented a platform of naked-eye point-of-care testing for detecting $\mathrm{pH}$, glucose and urea sensitively and visually just by observing the droplets state on the surface, so as to obtain the non-invasive diagnosis of diabetes for quantitative biosensing (Fig. 14) ${ }^{[166]}$.

Moreover, to meet the Sustainable Development Goals of United Nations (Zero Hunger, Clean Water and Sanitation), it is necessary to improve the ability of crops to resist the climate and increase the utilization rate of fertilizers and pesticide ${ }^{[167,168]}$. Gao et al. fabricated a switchable Light-Responsive Herbicide Nanosafener (LHNS) by using $\mathrm{TiO}_{2}$, biochar (BC) and hydrogen silicone oil, which provided a promising method for reducing the adverse effects of herbicides and improving the efficiency of foliar fertilizer utilization (Fig 15a ${ }^{[169]}$. Adjusted by ultraviolet light, the hydrophobic surface changed into hydrophilic surface because of the presence of $\mathrm{TiO}_{2}$, thereby increasing the adhesion of urea and promoting the growth of crops. Under infrared (IR) light, the photothermal effect of $\mathrm{BC}$ decreased the water absorption, so that the hydrophobic surface can be used as a glycine safener. In order to quickly and accurately detect the trace level picloram (PCR) in agriculture and environment, Mutharani et al. adopted poly(N-vinylcaprolactam) and multi-walled carbon nanotubes (MWCNT-PVCL) onto the electrochemical sensors with gold nanoparticles (Fig. 15b) ${ }^{[170]}$. Using 

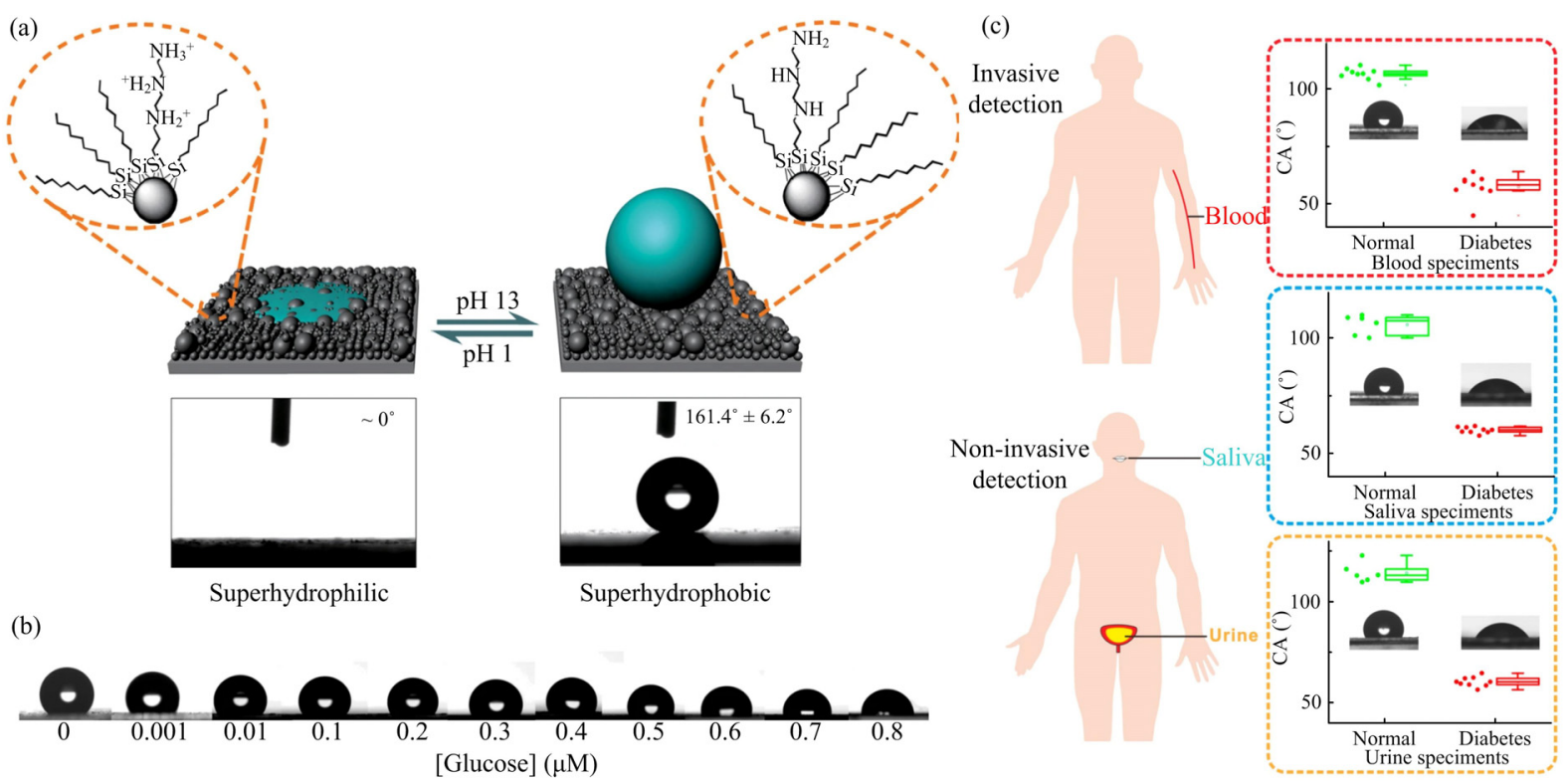

Fig. 14 (a) Working principle of the switching of the pH-responsive superwetting surface properties. (b) Changes of wetting states of droplets with different concentrations of urea or glucose. (c) Visual quantitative detection of glucose in practical settings ${ }^{[166]}$.

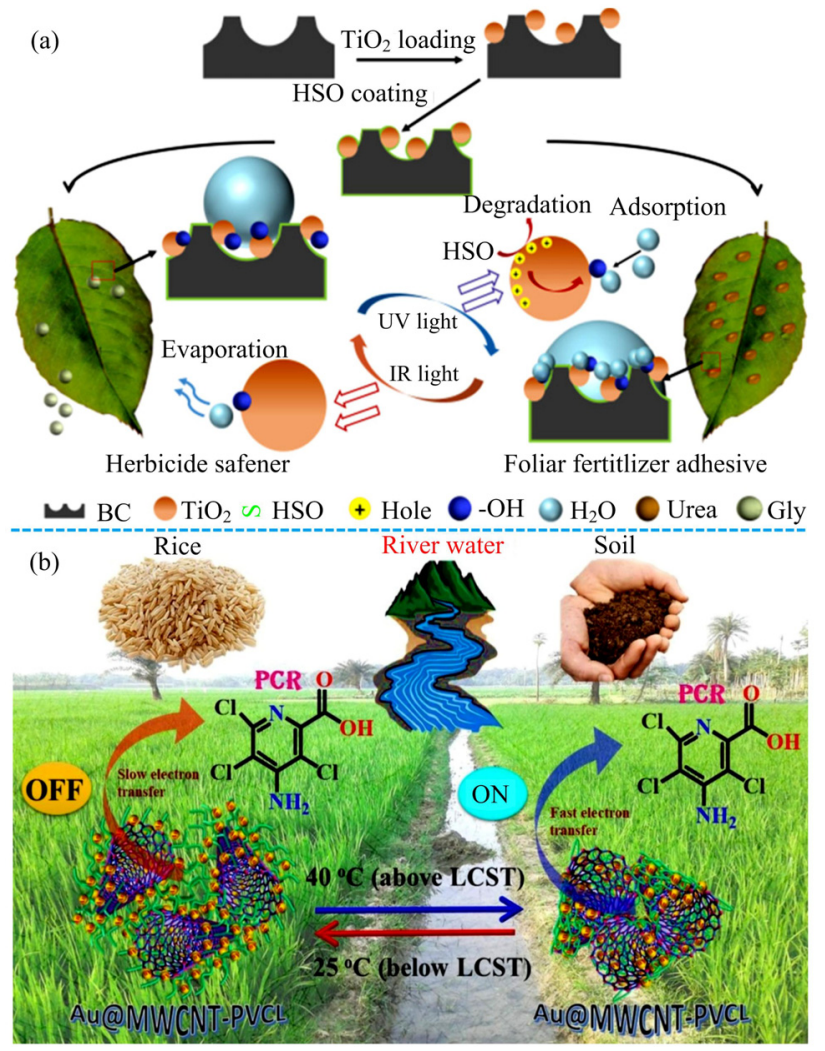

Fig. 15 (a) The light-responsive smart surface used for herbicide safener or foliar fertilizer adhesive, hydrophilic LHNS can improved the adhesion of foliar fertilizer; hydrophobic LHNS can prevent the adsorption of the amount of water and used as a glycine safener ${ }^{[169]}$. (b) The smart surface upon temperature for PCR detection, the hydrophilic surface of PVCL at $25{ }^{\circ} \mathrm{C}$ prevent the PCR pass over in "OFF" state, while the switched hydrophobic surface at $40{ }^{\circ} \mathrm{C}$ upgrade PCR oxidation in "ON" state ${ }^{[170]}$. the temperature-sensitive catalyst characteristics, it can be used to realize the conversion of surface wettability and affect the electrocatalytic active sites, so as to realize the controllable and selective detection of PCR, with a $1.5 \mathrm{nM}$ limitation of detection for PCR at $40{ }^{\circ} \mathrm{C}$.

\subsection{Smart soft robotic}

As an emerging field, soft robotics combines traditional robotics with material science and chemistry to improve performance by implementing novel hardware concepts and functions ${ }^{[171]}$. As mentioned in above, the control of switchable surface wettability mostly is caused by the properties a wide range of material. Inspired by multimodal locomotive strategies of insects, Chen et al. reported a hybrid terrestrial-aquatic robot by using electrowetting to control surface tension magnitude, realizing the transition between water surface and underwater $^{[172]}$. With the effects of electrical signal on the all four EWPs, the microrobot made use of the combination of surface tension and buoyancy to achieve controllable sinking (Fig. 16a). Moreover, the microrobot could overcome surface tension and climb a modest incline to transition back onto land, exhibiting unique locomotive capabilities (Fig. 16b).

Usually, such as the capability of droplet capture, storage, release, and pumpless transportation by the 


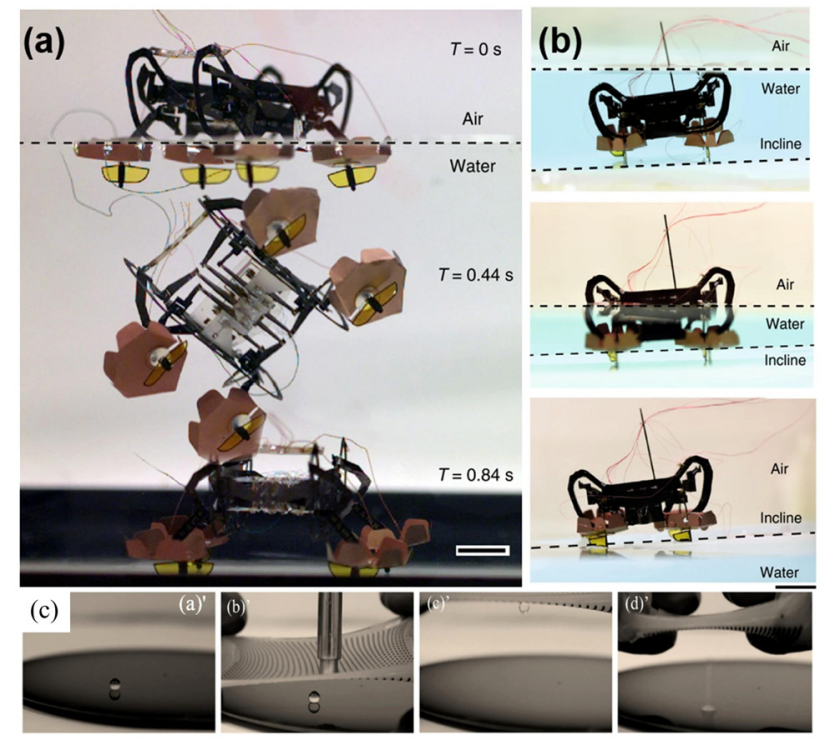

Fig. 16 (a) Images of a robot sinking into water with a $600 \mathrm{~V}$ signal on the all four EWPs ${ }^{[172]}$. Scale bars is $5 \mathrm{~mm}$. (b) The robot climbs an incline from fully submerged in water, the air-water interface, to completely exiting water ${ }^{[172]}$. Scale bar is $1 \mathrm{~cm}$. (c) Droplet pick-and-place with the composite surface on a $\mathrm{Si}$ wafer $^{[174]}$.

reversible changes in surface adhesion can be used as a "mechanical hand" for no-loss droplet transfer ${ }^{[87,106,108,173]}$. A black silicon/elastomer composite surface with highly flexibility was designed by Park and coworkers, which presented switchable wettability as well as adhesion transformation between slippery lotus and adhesive rose petal states under various mechanical strains ${ }^{[174]}$. Moreover, due to this characteristic, the self-propulsion and pick-and-place of water droplets were obtained, which was expected to be used in microfluidic field (Fig. 16c). Wang et al. introduced a mechano-regulated device to capture, transport and release oil droplets by moving microfiber array, exhibiting the water-droplet-capturing surface of dandelion seeds and water-droplet-repelling surfaces of lotus leaves ${ }^{[175]}$.

In addition, the smart surface with switchable wettability can not only control the adhesion of droplets but also the gas and underwater oil, further helping to provide new opportunities for the development of smart switchable surfaces. Guo's team produced a smart superwetting surface with the properties of manipulation oil droplets and bubbles underwater via switchable adhesion upon ultraviolet response ${ }^{[176]}$. Liu et al. reported a novel oil-triggered surface by switching wettability property between lotus-leaf and nepenthes, which was used in various droplet manipulation modes with real-time property ${ }^{[121]}$.

Last but not least, smart wettable surfaces are also used in other fields, condensation heat transfer ${ }^{[177]}$, self-cleaning prints ${ }^{[178]}$, smart textile ${ }^{[179]}$, encryption ${ }^{[180]}$ and so on. There is no doubt that smart surfaces with switchable wettability will bring progress to our lives, and provide new ideas and approaches for the development of industrial sets, biomedical materials and smart agricultural materials.

\section{Conclusions and outlook}

In this review, we have reviewed the several interfacial superwetting states based on the surface of natural creatures with special microstructures, including special wetting models and liquid adhesive behaviors, so as to provide wetting mechanisms for switchable wettability on superwettable materials. At the same time, we focus on the recent advances in different smart surfaces in response to external stimuli, mainly including physical stimuli (such as temperature, light, electric field, magnetic, stress), chemical stimuli (like $\mathrm{pH}$, ions and solvents), and dual or multiple stimuli. By analyzing the responsive mechanism under different stimulus, we can find that the surface wettability transition is mainly caused by the transformation of the surface chemical composition, surface energy or surface microstructures. Simultaneously, with the introduction of the responsive materials, the surface wettability is controllable, effectively expanding the surface functional properties, so that these surfaces can be applied in oil/water separation, liquid manipulation, anti-biofouling, detection and delivery fields etc.

In summary, the smart wettability surfaces have made several progresses in recent years, but there still remain many problems. Firstly, the use of responsive materials should be environmentally friendly. Secondly, most of the surface responsiveness is single stimuli, which greatly limits its application fields. The complexity of the factual environment determines the surface to have multiple response characteristics. Aiming at meeting diverse requirements in different application environments, diverse smart surfaces should be further exploited. Thirdly, high sensitivity, fast response, repeatable response times, and responsive range are very 
critical. The electrical response speed is relatively fast, but the responsive process such as light and temperature requires a relatively long time. At the same time, there are problems with narrow response range, such as smaller response temperature span, smaller $\mathrm{pH}$ response range, broader responsive optical wavelength, etc. Fourthly, complex preparation procedures greatly limit the possibility of its application in production, so it is currently limited to laboratory research. In order to solve the aforementioned problems, the construction of smart surfaces should be emphasized on the environmentally-friendly materials, low cost, facile preparation process. Recently, smart materials provide a wider range of materials for 3D printing technology and expand the concept of 4D printing, which will be more conducive to the development of smart surfaces in the future. Last but not least, the mechanical and chemical long-term stability is critical in determining whether the smart surfaces can be successfully used in the actual applications. Therefore, how to bind the responsive materials onto the substrate tightly should also be a major concern in the future. Nevertheless, there will also emerge lots of opportunities in the field of intelligent transformation of bioinspired superwettability, including new bio-inspirations, coupled strategies, versatility and novel applications.

\section{Acknowledgment}

The authors thank the National Natural Science Foundation of China (No. 51775231), National Postdoctoral Program for Innovative Talents (BX20180123), China Postdoctoral Science Foundation (2018M641782), Scientific Research Project of Jilin Provincial Department of Education (JJKH20211117KJ) and JLU Science and Technology Innovative Research Team (No. 2017TD-04).

Open Access This article is licensed under a Creative Commons Attribution 4.0 International License, which permits use, sharing, adaptation, distribution and reproduction in any medium or format, as long as you give appropriate credit to the original author(s) and the source, provide a link to the Creative Commons licence, and indicate if changes were made.

The images or other third party material in this article are included in the article's Creative Commons licence, unless indicated otherwise in a credit line to the material. If material is not included in the article's Creative Commons licence and your intended use is not permitted by statutory regulation or exceeds the permitted use, you will need to obtain permission directly from the copyright holder.

To view a copy of this licence, visit http://creativecommons.org/licenses/by/4.0/.

\section{References}

[1] Xu W H, Zheng H X, Liu Y, Zhou X F, Zhang C, Song Y X, Deng X, Leung M, Yang Z B, Xu R X, Wang Z L, Zeng X C, Wang Z K. A droplet-based electricity generator with high instantaneous power density. Nature, 2020, 578, 392-396.

[2] Lambley H, Schutzius T M, Poulikakos D. Superhydrophobic surfaces for extreme environmental conditions. PNAS, 2020, 117, 27188-27194.

[3] Feng S L, Delannoy J, Malod A, Zheng H X, Quéré D, Wang Z K. Tip-induced flipping of droplets on Janus pillars: From local reconfiguration to global transport. Science Advances, 2020, 6, eabb4540

[4] Li J, Ha N S, Liu T', van Dam R M, Kim C J. Ionic-surfactant-mediated electro-dewetting for digital microfluidics. Nature, 2019, 572, 507-510.

[5] Liu M J, Wang S T, Jiang L. Nature-inspired superwettability systems. Nature Reviews Materials, 2017, 2, 17036.

[6] Kuroki H, Tokarev I, Minko S. Responsive surfaces for life science applications. Annual Review of Materials Research, 2012, 42, 343-372.

[7] Barthlott W, Neinhuis C. Purity of the sacred lotus, or escape from contamination in biological surfaces. Planta, 1997, 202, $1-8$.

[8] Feng L, Li S H, Li Y S, Li H J, Zhang L J, Zhai J, Song Y L, Liu B Q, Jiang L, Zhu D B. Super-hydrophobic surfaces: From natural to artificial. Advanced Materials, 2002, 14, $1857-1860$

[9] Feng L, Zhang Y N, Xi J M, Zhu Y, Wang N, Xia F, Jiang L. Petal effect: A superhydrophobic state with high adhesive force. Langmuir, 2008, 24, 4114-4119.

[10] Wong T S, Kang S H, Tang S K Y, Smythe E J, Hatton B D, Grinthal A, Aizenberg J. Bioinspired self-repairing slippery surfaces with pressure-stable omniphobicity. Nature, 2011, 477, 443-447.

[11] Gao X F, Yan X, Yao X, Xu L, Zhang K, Zhang J H, Yang B, Jiang L. The dry-style antifogging properties of mosquito compound eyes and artificial analogues prepared by soft li- 
thography. Advanced Materials, 2010, 19, 2213-2217.

[12] Gao X, Jiang L. Biophysics: Water-repellent legs of water striders. Nature, 2004, 432, 36.

[13] Parker A R, Lawrence C R. Water capture by a desert beetle. Nature, 2001, 414, 33-34.

[14] Wang G Y, Guo Z G, Liu W M. Interfacial effects of superhydrophobic plant surfaces: A review. Journal of Bionic Engineering, 2014, 11, 325-345.

[15] Zhang S N, Huang J Y, Chen Z, Yang S, Lai Y K. Liquid mobility on superwettable surfaces for applications in energy and the environment. Journal of Materials Chemistry A, 2019, 7, 38-63.

[16] Cao M Y, Guo D W, Yu C M, Li K, Liu M J, Jiang L. Water-repellent properties of superhydrophobic and lubricant-infused "slippery" surfaces: A brief study on the functions and applications. ACS Applied Materials \& Interfaces, 2016, 8, 3615-3623.

[17] Zhang P C, Lin L, Zang D M, Guo X L, Liu M J. Designing bioinspired anti-biofouling surfaces based on a superwettability strategy. Small, 2017, 13, 1503334.

[18] Falde E J, Yohe S T, Colson Y L, Grinstaff M W. Superhydrophobic materials for biomedical applications. Biomaterials, 2016, 104, 87-103.

[19] Pan R, Zhang H J, Zhong M L. Triple-scale superhydrophobic surface with excellent anti-icing and icephobic performance via ultrafast laser hybrid fabrication. ACS Applied Materials \& Interfaces, 2021, 13, 1743-1753.

[20] Kim W, Kim D, Park S, Lee D, Hyun H, Kim J. Engineering lotus leaf-inspired micro- and nanostructures for the manipulation of functional engineering platforms. Journal of Industrial \& Engineering Chemistry, 2018, 61, 39-52.

[21] Li S Y, Liu Y, Zheng Z H, Liu X, Huang H L, Han Z W, Ren L Q. Biomimetic robust superhydrophobic stainless-steel surfaces with antimicrobial activity and molecular dynamics simulation. Chemical Engineering Journal, 2019, 372, 852-861.

[22] Li D W, Wang H Y, Liu Y, Wei D S, Zhao Z X. Large-scale fabrication of durable and robust super-hydrophobic spray coatings with excellent repairable and anti-corrosion performance. Chemical Engineering Journal, 2019, 367, 169-179.

[23] Wang Y F, Ma K K, Xin J H. Stimuli-responsive bioinspired materials for controllable liquid manipulation: Principles, fabrication, and applications. Advanced Functional Materials, 2017, 28, 1705128.

[24] Lou X D, Huang Y, Yang X, Zhu H, Heng L P, Xia F. External stimuli responsive liquid-infused surfaces switching between slippery and nonslippery states: Fabrications and applications. Advanced Functional Materials, 2020, 30, 1901130.

[25] Cheng Z J, Zhang D J, Luo X, Lai H, Liu Y Y, Jiang L. Superwetting shape memory microstructure: Smart wetting control and practical application. Advanced Materials, 2020, 200178 .

[26] Shao Y L, Zhao J, Fan Y, Wan Z P, Lu L S, Zhang Z H, Ming W H, Ren L Q. Shape memory superhydrophobic surface with switchable transition between "lotus effect" to "rose petal effect". Chemical Engineering Journal, 2020, 382, 122989.

[27] Zong C Y, Hu M, Azhar U, Chen X, Zhang Y B, Zhang S X, $\mathrm{Lu} \mathrm{C} \mathrm{H.} \mathrm{Smart} \mathrm{copolymer-functionalized} \mathrm{flexible} \mathrm{surfaces}$ with photoswitchable wettability: From superhydrophobicity with "rose petal" effect to superhydrophilicity. ACS Applied Materials \& Interfaces, 2019, 11, 25436-25444.

[28] Chang B S, Zhang B, Sun T L. Smart polymers with special wettability. Small, 2017, 13, 1503472.

[29] Kang H J, Liu Y Y, Lai H, Yu X Y, Cheng Z J, Jiang L. Under-oil switchable superhydrophobicity to superhydrophilicity transition on $\mathrm{TiO}_{2}$ nanotube arrays. ACS Nano, 2018, 12, 1074-1082.

[30] Young, T. An essay on the cohesion of fluids. Philosophical Transactions of the Royal Society of London, 1805, 95, $65-87$.

[31] Wenzel R N. Resistance of solid surfaces to wetting by water. Transactions of the Faraday Society, 1936, 28, 988-994.

[32] Cassie A B D, Baxter S. Wettability of porous surfaces. Transactions of the Faraday Society, 1944, 40, 546-551.

[33] Uchida K, Nishikawa N, Izumi N, Yamazoe S, Mayama H, Kojima Y, Yokojima S, Nakamura S, Tsujii K, Irie M. Phototunable diarylethene microcrystalline surfaces: Lotus and petal effects upon wetting. Angewandte Chemie-International Edition, 2010, 49, 5942-5944.

[34] Liu M J, Wang S T, Wei Z X, Song Y L, Jiang L. Bioinspired design of a superoleophobic and low adhesive water/solid interface. Advanced Materials, 2009, 21, 665.

[35] Chen H W, Zhang P F, Zhang L W, Liu H L, Jiang Y, Zhang D Y, Han Z W, Jiang L. Continuous directional water transport on the peristome surface of Nepenthes alata. $\mathrm{Na}$ ture, 2016, 532, 85-89.

[36] Zheng Y M, Gao X F, Jiang L. Directional adhesion of superhydrophobic butterfly wings. Soft Matter, 2007, 3, 178-182.

[37] Bixler G D, Bhushan B. Fluid drag reduction and efficient self-cleaning with rice leaf and butterfly wing bioinspired 
surfaces. Nanoscale, 2013, 5, 7685-7710.

[38] McHale G, Ledesma-Aguilar R, Wells G G. Interfacial strategies for smart slippery surfaces. Journal of Bionic Engineering, 2020, 17, 633-643.

[39] Liu X C, Yang F C, Guo J, Fu J, Guo Z G. New insights into unusual droplets: From mediating the wettability to manipulating the locomotion modes. Chemical Communications, 2020, 56, 14757-14788.

[40] Liu M J, Jiang L. Dialectics of nature in materials science: Binary cooperative complementary materials. Science China Materials, 2016, 59, 239-246.

[41] Chen L B, Yang T, Niu Y, Mu X, Gong Y L, Feng Y C, Rooij N F, Wang Y, Li H, Zhou G F. Building a smart surface with converse temperature-dependent wettability based on poly(acrylamide-co-acrylonitrile). Chemical Communication, 2020, 56, 2837-2840.

[42] Song Y Y, Liu Y, Jiang H B, Li S Y, Kaya C, Stegmaier T, Han Z W, Ren L Q. Temperature-tunable wettability on bioinspired structured graphene surface for fog collection and unidirectional transport. Nanoscale, 2018, 10, 3813-3822.

[43] Velayi E, Norouzbeigi R. Annealing temperature dependent reversible wettability switching of micro/nano structured $\mathrm{ZnO}$ superhydrophobic surfaces. Applied Surface Science, 2018, 441, 156-164.

[44] Banuprasad T N, Vinay T V, Subash C K, Varghese S, George S D, Varanakkottu S N. Fast transport of water droplets over a thermo-switchable surface using rewritable wettability gradient. ACS Applied Materials \& Interfaces, 2017, 9, 28046-28054.

[45] Wang B L, Xu Q W, Ye Z, Liu H H, Lin Q K, Nan K H, Li Y Z, Wang Y, Qi L, Chen H. Copolymer brushes with temperature-triggered, reversibly switchable bactericidal and antifouling properties for biomaterial surfaces. ACS Applied Materials \& Interfaces, 2016, 8, 27207-27217.

[46] Chang L, Liu H L, Ding Y, Zhang J J, Li L, Zhang X Q, Liu M Z, Jiang L. A smart surface with switchable wettability by an ionic liquid. Nanoscale, 2017, 9, 5822-5827.

[47] Liu Y, Tas S, Zhang K H, Vos W M, Ma J H, Vancso G J. Thermoresponsive membranes from electrospun mats with switchable wettability for efficient oil/water separations. Macromolecules, 2018, 51, 8435-8442.

[48] Su B, Guo W, Jiang L. Learning from nature: Binary cooperative complementary nanomaterials. Small, 2015, 11, 1072-1096.

[49] Zhang W F, Liu N, Zhang Q D, Qu R X, Liu Y N, Li X Y, Wei Y, Feng L, Jiang L. Thermo-driven controllable emul- sion separation by a polymer decorated membrane with switchable wettability. Angewandte Chemie International Edition, 2018, 57, 5740-5745.

[50] Wang J H, Huang Y, You K, Yang X, Song Y J, Zhu H, Xia F, Jiang L. Temperature-driven precise control of biological droplet's adhesion on a slippery surface. ACS Applied Materials \& Interfaces, 2019, 11, 7591-7599.

[51] Zhou Q N, Long M Y, Wen N, Deng W S, Deng W L. Rapid reversible superwettability transition and controllable oil/water separation based on hierarchical CuO. Surface \& Coatings Technology, 2019, 374, 144-151.

[52] Liu Y, Yao W G, Yin X M, Wang H Y, Han Z W, Ren L Q. Controlling wettability for improved corrosion inhibition on magnesium alloy as biomedical implant materials. Advanced Materials Interfaces, 2016, 3, 1500723.

[53] Zang D M, Zhu R W, Zhang W, Yu X Q, Lin L, Guo X L, Liu M J, Jiang L. Corrosion-resistant superhydrophobic coatings on $\mathrm{Mg}$ alloy surfaces inspired by Lotus Seedpod. Advanced Functional Materials, 2017, 27, 1605446.

[54] Zhang X, Guo Y G, Zhang P Y, Wu Z S, Zhang Z J. Superhydrophobic and superoleophilic nanoparticle film: Synthesis and reversible wettability switching behavior. ACS Applied Materials \& Interfaces, 2012, 4, 1742-1746.

[55] Pan Y L, Kong W T, Bhushan B, Zhao X Z. Rapid, ultraviolet-induced, reversibly switchable wettability of superhydrophobic/superhydrophilic surfaces. Beilstein Journal of Nanotechnology, 2019, 10, 866-873.

[56] Raturi P, Yadav K, Singh J P. ZnO-nanowires-coated smart surface mesh with reversible wettability for efficient on-demand oil/water separation. ACS Applied Materials \& Interfaces, 2017, 9, 6007-6013.

[57] Kamegawa T, Shimizu Y, Yamashita H. Superhydrophobic surfaces with photocatalytic self-cleaning properties by nanocomposite coating of $\mathrm{TiO}_{2}$ and polytetrafluoroethylene. Advanced Materials, 2012, 24, 3697-3700.

[58] Qing Y Q, Yang C N, Yu N N, Shang Y, Sun Y Z, Wang L S, Liu C S. Superhydrophobic $\mathrm{TiO}_{2} /$ polyvinylidene fluoride composite surface with reversible wettability switching and corrosion resistance. Chemical Engineering Journal, 2016, 290, 37-44.

[59] Yong J L, Chen F, Yang Q, Farooq U, Hou X. Photoinduced switchable underwater superoleophobicity-superoleophilicity on laser modified titanium surfaces. Journal of Materials Chemistry A, 2015, 3, 10703-10709.

[60] Li L J, Liu L, Lei J L, He J X, Li N B, Pan F S. Intelligent sponge with reversibly tunable super-wettability: Robust for effective oil-water separation as both the absorber and filter 
tolerate fouling and harsh environments. Journal of Materials Chemistry A, 2016, 4, 12334-12340.

[61] Qu R X, Liu Y N, Zhang W F, Li X Y, Feng L, Jiang L. Aminoazobenzene@Ag modified meshes with large extent photo-response: Towards reversible oil/water removal from oil/water mixtures. Chemical Science, 2019, 10, 4089-4096.

[62] Chen L F, Wang W Q, Su B, Wen Y Q, Li, C B, Zhou Y B, Li M Z, Shi X D, Du H W, Song Y L, Jiang L. A light-responsive release platform by controlling the wetting behavior of hydrophobic surface. ACS Nano, 2014, 8, 744-751.

[63] He D, Arisaka Y, Masuda K, Yamamoto M, Takeda N. A photo-responsive soft interface reversibly controls wettability and cell adhesion by conformational changes in a spiropyran conjugated amphiphilic block copolymer. Acta Biomaterialia, 2017, 51, 101-111.

[64] Petroffe G, Wang C, Sallenave X, Sini G, Goubard F, Pé ralta $\mathrm{S}$. Fast and reversible photo-responsive wettability on $\mathrm{TiO}_{2}$ based hybrid surfaces. Journal of Materials Chemistry A, 2015, 3, 11533-11542.

[65] Pan S J, Guo R, Xu W J. Photoresponsive superhydrophobic surfaces for effective wetting control. Soft Matter, 2014, 10, 9187-9192.

[66] Ichimura K, Oh S K, Nakagawa M. Light-driven motion of liquids on a photoresponsive surface. Science, 2000, 288, $1624-1626$

[67] Zong C Y, Hu M, Azhar U, Chen X, Zhang Y B, Zhang S X, $\mathrm{Lu}$ C H. Smart copolymer-functionalized flexible surfaces with photoswitchable wettability: From superhydrophobicity with "rose petal" effect to superhydrophilicity. ACS Applied Materials \& Interfaces, 2019, 11, 25436-25444.

[68] Kung C H, Zahiri B, Sow P K, Mérida W. On-demand oil-water separation via low-voltage wettability switching of core-shell structures on copper substrates. Applied Surface Science, 2018, 444, 15-27.

[69] Mugele F, Baret J C. Electrowetting: From basics to applications. Journal of Physics Condensed Matter, 2005, 17, R705-R774.

[70] Pernites R B, Santos C M, Maldonado M, Ponnapati R R, Rodrigues D F, Advincula R C. Tunable protein and bacterial cell adsorption on colloidally templated superhydrophobic polythiophene films. Chemistry of Materials, 2012, 24, 870-880.

[71] Zhang Q Q, Kang J X, Xie Z Q, Diao X G, Liu Z Y, Zhai J. Highly efficient gating of electrically actuated nanochannels for pulsatile drug delivery stemming from a reversible wettability switch. Advanced Materials, 2018, 30, 1703323.
[72] Guselnikova O, Elashnikov R, Postnikov P, Svorcik V, Lyutakov O. Smart, piezo-responsive polyvinylidenefluoride/polymethylmethacrylate surface with triggerable water/oil wettability and adhesion. ACS Applied Materials \& Interfaces, 2018, 10, 37461-37469.

[73] Lahann J, Mitragotri S, Tran T N, Kaido K, Sundaram J, Choi I S, Hoffer S, Somorjai G A, Langer R. A reversibly switching surface. Science, 2003, 299, 371-374.

[74] Wang Q B, Xu B J, Hao Q, Wang D, Liu H, Jiang L. In situ reversible underwater superwetting transition by electrochemical atomic alternation. Nature Communications, 2019, 10, 1212 .

[75] Zheng X, Guo Z Y, Tian D L, Zhang X F, Jiang L. Electric field induced switchable wettability to water on the polyaniline membrane and oil/water separation. Advanced Materials Interfaces, 2016, 3, 1600461.

[76] He X D, Qiang W B, Du C, Shao Q F, Zhang X P, Deng Y Q. Modification of lubricant infused porous surface for low-voltage reversible electrowetting. Journal of Materials Chemistry A, 2017, 5, 19159-19167.

[77] Krupenkin T N, Taylor J A, Schneider T M, Yang S. From rolling ball to complete wetting: The dynamic tuning of liquids on nanostructured surfaces. Langmuir, 2004, 20, 3824-3827.

[78] Kavousanakis M E, Chamakos N T, Ellinas K, Tserepi A, Gogolides E, Papathanasiou A G. How to achieve reversible electrowetting on superhydrophobic surfaces. Langmuir, 2018, 34, 4173-4179.

[79] Tian D L, Zhang N, Zheng X, Hou G L, Tian Y, Du Y, Jiang L, Dou S X. Fast responsive and controllable liquid transport on a magnetic fluid/nanoarray composite interface. $A C S$ Nano, 2016, 10, 6220-6226.

[80] Li Z W, Yang F, Yin Y D. Smart materials by nanoscale magnetic assembly. Advanced Functional Materials, 2020, 30, 1903467.

[81] Lee S H, Seong M, Kwak M K, Ko H, Kang M, Park H W, Kang S M, Jeong H E. Tunable multimodal drop bouncing dynamics and anti-icing performance of a magnetically responsive hair array. ACS Nano, 2018, 12, 10693-10702.

[82] Su X J, Li H Q, Lai X J, Zhang L, Liao X F, Wang J, Chen Z $\mathrm{H}$, He J, Zeng X R. Dual-functional superhydrophobic textiles with asymmetric roll-down/pinned states for water droplet transportation and oil-water separation. ACS Applied Materials \& Interfaces, 2018, 10, 4213-4221.

[83] Jiang S J, Hu Y L, Wu H, Zhang Y C, Zhang Y Y, Wang Y L, Zhang Y H, Zhu W L, Li J W, Wu D, Chu J R. Multifunctional Janus microplates arrays actuated by magnetic fields 
for water/light switches and bio-inspired assimilatory coloration. Advanced Materials, 2019, 31, 1807507.

[84] Wang J, Li H, Zou H Y, Wang C M, Zhang H, Manob J F Song W L. Flexible method for fabricating protein patterns on superhydrophobic platforms controlled by magnetic field. Biomaterials Science, 2017, 5, 408-411.

[85] Wang Z J, Cao J, Jia J S, Qi J L, Huang Y X, Feng J C. Making superhydrophobic surfaces with microstripe array structure by diffusion bonding and their applications in magnetic control microdroplet release systems. Advanced Materials Interfaces, 2017, 4, 1700918.

[86] Wang L, Gao C L Hou Y P, Zheng Y M, Jiang L. Magnetic field-guided directional rebound of a droplet on a superhydrophobic flexible needle surface. Journal of Materials Chemistry A, 2016, 4, 18289-18293.

[87] Yang C, Wu L, Li G. Magnetically responsive superhydrophobic surface: In situ reversible switching of water droplet wettability and adhesion for droplet manipulation. ACS Applied Materials \& Interfaces, 2018, 10, 20150-20158.

[88] Drotlef D M, Blümler P, Papadopoulos P, Campo A D. Magnetically actuated micropatterns for switchable wettability. ACS Applied Materials \& Interfaces, 2014, 6, 8702-8707.

[89] Huang Y, Stogin B B, Sun N, Wang J, Yang S K, Wong T S. A switchable cross-species liquid repellent surface. $A d$ vanced Materials, 2017, 29, 1604641.

[90] Park J K, Yang Z, Kim S. Black silicon/elastomer composite surface with switchable wettability and adhesion between lotus and rose petal effects by mechanical strain. ACS Applied Materials \& Interfaces, 2017, 9, 33333-33340.

[91] Zhang D J, Cheng Z J, Liu Y Y. Smart wetting control on shape memory polymer surfaces. Chemistry-A European Journal, 2019, 25, 3979-3992.

[92] Lv T, Cheng Z J, Zhang E S, Kang H J, Liu Y Y, Jiang L. Self-restoration of superhydrophobicity on shape memory polymer arrays with both crushed microstructure and damaged surface chemistry. Small, 2017, 13, 1503402.

[93] Lv T, Cheng Z J, Zhang D J, Zhang E S, Zhao Q L, Liu Y Y, Jiang L. Superhydrophobic surface with shape memory micro/nanostructure and its application in rewritable chip for droplet storage. ACS Nano, 2016, 10, 9379-9386.

[94] Cheng Z J, Zhang D J, Lv T, Lai H, Zhang E S, Kang H J, Wang Y Z, Liu P C, Liu Y Y, Du Y, Dou S X, Jiang L. Superhydrophobic shape memory polymer arrays with switchable isotropic/anisotropic wetting. Advanced Functional Materials, 2018, 28, 1705002.

[95] Wang J N, Liu Y Q, Zhang Y L, Feng J, Wang H, Yu Y H,
Sun H B. Wearable superhydrophobic elastomer skin with switchable wettability. Advanced Functional Materials, 2018, 28, 1800625.

[96] Wu D, Wu S Z, Chen Q D, Zhang Y L, Yao J, Yao X, Niu L G, Wang J N, Jiang L, Sun H B. Curvature-driven reversible in situ switching between pinned and roll-down superhydrophobic states for water droplet transportation. Advanced Materials, 2011, 23, 545-549.

[97] Yan S J, Shi H C, Song L J, Wang X H, Liu L, Luan S F, Yang Y M, Yin J H. Nonleaching bacteria-responsive antibacterial surface based on a unique hierarchical architecture. ACS Applied Materials \& Interfaces, 2016, 8, 24471-24481.

[98] Wei T, Yu Q, Zhan W J, Chen H. A smart antibacterial surface for the on-demand killing and releasing of bacteria. Advanced Healthcare Materials, 2016, 5, 449-456.

[99] Cheng M J, Liu Q, Ju G N, Zhang Y J, Jiang L, Shi F. Bell-shaped superhydrophilic-superhydrophobic-superhydro philic double transformation on a $\mathrm{pH}-$ responsive smart surface. Advance Materials, 2014, 26, 306-310.

[100] Dang Z, Liu L, B, Li Y, Xiang Y, Guo G L. In situ and ex situ $\mathrm{pH}$-responsive coatings with switchable wettability for controllable oil/water separation. ACS Applied Materials \& Interfaces, 2016, 8, 31281-31288.

[101] Zeng X J, Yang K Q, Huang C Y, Yang K, Xu S P, Wang L, Pi P H, Wen X F. Novel pH-responsive smart fabric: From switchable wettability to controllable on-demand oil/water separation. ACS Sustainable Chemistry Engineering, 2019, 7, 368-376.

[102] Cheng M X, He H, Zhu H X, Wei Guo W, Chen W B, Xue F, Zhou S L, Chen X J, Wang S F. Preparation and properties of pH-responsive reversible-wettability biomass cellulose-based material for controllable oil/water separation. Carbohydrate Polymers, 2019, 203, 246-255.

[103] Cai Y H, Chen D Y, Li N J, Xu Q F, Li H, He J H, Lu J M. A smart membrane with antifouling capability and switchable oil wettability for high-efficiency oil/water emulsions separation. Journal of Membrane Science, 2018, 555, 69-77.

[104] Li X Y, Zhang Q D, Zhang W F, Qu R X, Wei Y, Feng L. Smart nylon membranes with $\mathrm{pH}$-responsive wettability: High-efficiency separation on demand for various oil/water mixtures and surfactant-stabilized emulsions. Advanced Materials Interfaces, 2018, 5, 1801179.

[105] Liu Y, Zhang K T, Son Y, Zhang W, Spindler L M, Han Z W, Ren L Q. A smart switchable bioinspired copper foam responding to different $\mathrm{pH}$ droplets for reversible oil-water separation. Journal of Materials Chemistry A, 2017, 5, 2603-2612. 
[106] Gao H P, Liu Y, Li S Y, Wang G Y, Han Z W, Ren L Q. A biomimetic surface with switchable contact angle and adhesion for transfer and storage of microdroplets. Nanoscale, 2018, 10, 15393-15401.

[107] Liu Y, Yao W G, Wang G Y, Ana S M, Han Z W, Ren L Q. Reversibly switchable wettability on aluminum alloy substrate corresponding to different $\mathrm{pH}$ droplet and its corrosion resistance. Chemical Engineering Journal, 2016, 303, 565-574.

[108] Liu Y, Gao H P, Li S Y, Han Z W, Ren L Q. Bioinspired platform with reversibly switchable wettability for transfer and storage of droplets. Chemical Engineering Journal, 2018, 337, 697-708.

[109] Zhang G Y, Zhang X, Li M, Su Z H. A surface with superoleophilic-to-superoleophobic wettability gradient. ACS Applied Materials \& Interfaces, 2014, 6, 1729-1733.

[110] Wang L M, Lin Y, Peng B, Su Z H. Tunable wettability by counterion exchange at the surface of electrostatic self-assembled multilayers. Chemical Communication, 2008, 45, 5972-5974.

[111] Jiang C, Wang Q H, Wang T M. Tunable wettability via counterion exchange of polyelectrolyte brushes grafted on cotton fabric. New Journal of Chemistry, 2012, 36, $1641-1645$.

[112] Yang J, Zhang Z Z, Men X H, Xu X H, Zhu X T, Zhou X Y. Counterion exchange to achieve reversibly switchable hydrophobicity and oleophobicity on fabrics. Langmuir, 2011, 27, 7357-7360.

[113] Mosnáček J, Popelka A, Osicka J, Filip J, Ilcikova M, Kollar J, Yousaf A B, Bertok T, Tkac J, Kasaka P. Modulation of wettability, gradient and adhesion on self-assembled monolayer by counterion exchange and $\mathrm{pH}$. Journal of Colloid \& Interface Science, 2018, 512, 511-521

[114] Osicka J, Ilcikova M, Popelka A, Filip J, Bertok T, Tkac J, Kasak P. Simple, reversible and fast modulation in superwettability, gradient and adsorption by counterion exchange on self-assembled monolayer. Langmuir, 2016, 32, 5491-5499.

[115] Yang J T, Chen H, Xiao S W, Shen M X, Chen F, Fan P, Zhong M Q, Zheng J. Salt-responsive zwitterionic polymer brushes with tunable friction and antifouling properties. Langmuir, 2015, 31, 9125-9133.

[116] Chen H, Yang J T, Xiao S W, Hu R D, Bhaway S M, Vogt B D, Zhang M Z, Chen Q, Ma J, Chang Y, Li L Y, Zheng J. Salt-responsive polyzwitterionic materials for surface regeneration between switchable fouling and antifouling properties. Acta Biomaterialia, 2016, 40, 62-69.
[117] Xu L X, Liu N, Cao Y Z, Chen Y N, Zhang X Y, Feng L, Wei Y. Mercury ion responsive wettability and oil/water separation. ACS Applied Materials \& Interfaces, 2014, 6, 13324-13329.

[118] Ding Y C, Xu W H, Yu Y, Hou H Q, Zhu Z T. One-step preparation of highly hydrophobic and oleophilic melamine sponges via metal-ion induced wettability transition. ACS Applied Materials \& Interfaces, 2018, 10, 6652-6660.

[119] Frenzel R, Höhne S, Hanzelmann C, Schmidt T, Winkler R, Drechsler A, Bittrich E, Eichhorn K J, Uhlmann P. Tunable hydrophilic or amphiphilic coatings: A "reactive layer stack" approach. ACS Applied Materials \& Interfaces, 2015, 7, 12355-12366.

[120] Tatry M C, Qiu Y T, Lapeyre V, Garrigue P, Schmitt V, Ravain V. Sugar-responsive Pickering emulsions mediated by switching hydrophobicity in microgels. Journal of Colloid and Interface Science, 2020, 561, 481-493.

[121] Liu W J, Pan R, Cai M Y, Luo X, Chen C H, Jiang G C, Hu X Y, Zhang H J, Zhong M L. Oil-triggered switchable wettability on patterned alternating air/lubricant-infused superamphiphobic surfaces. Journal of Materials Chemistry A, 2020, 8, 6647-6660.

[122] Pan Y L, Liu L M, Zhang Z J, Huang S C, Hao Z, Zhao X Z. Surfaces with controllable super-wettability and applications for smart oil-water separation. Chemical Engineering Journal, 2019, 378, 122178

[123] Hamley I W. Nanotechnology with soft materials. Angewandte Chemie International Edition, 2003, 42, 1692-1712.

[124] Wang Y, Di J C, Wang L, Li X, Wang N, Wang B X, Tian Y, Jiang L, Yu J H. Infused-liquid-switchable porous nanofibrous membranes for multiphase liquid separation. Nature Communication, 2017, 8, 575.

[125] Song Y Y, Liu Y, Jiang H B, Xue J Z, Yu Z P, Li S Y, Han Z $\mathrm{W}$, Ren L Q. Janus soft actuators with on-off switchable behaviors for controllable manipulation driven by oil. ACS Applied Materials \& Interfaces, 2019, 11, 13742-13751.

[126] Yong J L, Yang Q, Chen F, Bian H, Du G Q, Farooq U, Hou $\mathrm{X}$. Reversible underwater lossless oil droplet transportation. Advanced Materials Interfaces, 2015, 2, 1400388.

[127] Frysali M A, Anastasiadis S H. Temperature- and/or pHresponsive surfaces with controllable wettability: From parahydrophobicity to superhydrophilicity. Langmuir, 2017, 33, 9106-9114.

[128] ElSherbiny I M A, Khalil A S G, Ulbricht M. Tailoring surface characteristics of polyamide thin-film composite membranes toward pronounced switchable wettability. Advanced Materials Interfaces, 2019, 6, 1801408. 
[129] Rao Q Q, Li A, Zhang J W, Jiang J X, Zhang Q H, Zhan X L, Chen F Q. Multi-functional fluorinated ionic liquid infused slippery surfaces with dual-responsive wettability switching and self-repairing. Journal of Materials Chemistry A, 2019, 7, 2172-2183.

[130] Ma W J, Samal S K, Liu Z C. Dual pH- and ammonia-vapor-responsive electrospun nanofibrous membranes for oil-water separations. Journal of Membrane Science, 2017, 537, 128-139.

[131] Wang Y X, Liu Z Y, Guo X H, Zhao L Y, Li L, Meng G H, $\mathrm{Wu} J$ N. Preparation and characterization of thermo- and $\mathrm{pH}$ dual-responsive 3D cellulose-based aerogel for oil/water separation. Applied Physics A-Materials Science \& Processing, 2018, 124, 9.

[132] Huang X, Sun Y J, Soh S. Stimuli-responsive surfaces for tunable and reversible control of wettability. Advanced Materials, 2015, 27, 4062-4068.

[133] Zhang D J, Cheng Z J, Lai H, Kang H J, Yu J X, Liu Y Y, Jiang L. Smart superwetting surface with responsivity in both surface chemistry and microstructure. Angewandte Chemie International Edition, 2018, 57, 3701-3705.

[134] Ren J P, Tao F R, Liu L B, Wang X, Cui, Y Z. A novel $\mathrm{TiO}_{2} @$ stearic acid/chitosan coating with reversible wettability for controllable oil/water and emulsions separation. Carbohydrate Polymers, 2020, 232, 115807.

[135] Pan Y L, Liu L M, Zhang Z J, Huang S C, Hao Z, Zhao X Z. Surfaces with controllable super-wettability and applications for smart oil-water separation. Chemical Engineering Journal, 2019, 378, 122178.

[136] Liu Y, Zhan B, Zhang K T, Kaya C, Stegmaier T, Han Z W, Ren L Q. On-demand oil/water separation of 3D Fe foam by controllable wettability. Chemical Engineering Journal, 2018, 311, 278-289.

[137] Zhan B, Liu Y, Li S Y, Cigdem K, Thomas S, Maryam A, Han Z W, Ren L Q. Fabrication of superwetting $\mathrm{Cu} @ \mathrm{Cu}_{2} \mathrm{O}$ cubic film for oil/water emulsion separation and photocatalytic degradation. Applied Surface Science, 2019, 496, 143580.

[138] Yang W W, Li J, Zhou P, Zhu L H, Tang H Q. Superhydrophobic copper coating: Switchable wettability, on-demand oil-water separation, and antifouling. Chemical Engineering Journal, 2017, 327, 849-854.

[139] Zhang X, Chen Q, Wei R, Jin L Q, He C, Zhao W F, Zhao C $\mathrm{S}$. Design of poly ionic liquids modified cotton fabric with ion species-triggered bidirectional oil-water separation performance. Journal of Hazardous Materials, 2020, 400, 123163.
[140] Wang F, Pi J, Li J Y, Song F, Feng R, Wang X L, Wang Y Z. Highly-efficient separation of oil and water enabled by a silica nanoparticle coating with $\mathrm{pH}$-triggered tunable surface wettability. Journal of Colloid and Interface Science, 2019, 557, 65-75.

[141] Tie L, Zhao S Y, Guo Z G, Li J. Fine switching between underwater superoleophilicity and underwater superoleophobicity while maintaining superhydrophobicity. Langmuir, 2020, 36, 3300-3307.

[142] Li L J, Rong L D, Xu Z T, Wang B J, Feng X L, Mao Z P, Xu H, Yuan J Y, Liu S Q, Sui X F. Cellulosic sponges with $\mathrm{pH}$ responsive wettability for efficient oil-water separation. Carbohydrate Polymers, 2020, 237, 116133.

[143] Li J J, Zhou Y N, Luo Z H. Polymeric materials with switchable superwettability for controllable oil/water separation: A comprehensive review. Progress in Polymer Science, 2018, 87, 1-33.

[144] Raturi P, Yadav K, Singh J P. ZnO-nanowires-coated smart surface mesh with reversible wettability for efficient on-demand oil/water separation. ACS Applied Materials \& Interfaces, 2017, 9, 6007-6013.

[145] Zhang H Y, Lai H, Cheng Z J, Zhang D J, Liu P C, Li Y F, Liu Y Y. In-situ switchable superhydrophobic shape memory microstructure patterns with reversible wettability and adhesion. Applied Surface Science, 2020, 525, 146525.

[146] Malinowski R, P Parkin I, Volpe G. Advances towards programmable droplet transport on solid surfaces and its applications. Chemical Society Reviews, 2020, 49, 7879-7892.

[147] Sun L Y, Bian F K, Wang Y, Wang Y T, Zhang X X, Zhao Y J. Bioinspired programmable wettability arrays for droplets manipulation. Proceedings of the National Academy of Sciences of the United States of America, 2020, 117, $4527-4532$.

[148] Zhang L, Zhao J X, Xu J Y, Zhao J Q, Zhu Y T, Li Y J, You J C. Switchable isotropic/anisotropic wettability and programmable droplet transportation on a shape-memory honeycomb. ACS Applied Materials \& Interfaces, 2020, 12, 42314-42320.

[149] Zhang Q Y, He L L, Zhang X F, Tian D L, Jiang L. Switchable direction of liquid transport via an anisotropic microarray surface and thermal stimuli. ACS Nano, 2020, 14, 1436-1444.

[150] Li D K, Huang J X, Han G C, Guo Z G. A facile approach to achieve bioinspired PDMS@ $\mathrm{Fe}_{3} \mathrm{O}_{4}$ fabric with switchable wettability for liquid transport and water collection. Journal of Materials Chemistry A, 2018, 6, 22741-22748. 
[151] Li Z H, Guo Z G. Bioinspired surfaces with wettability for antifouling application. Nanoscale, 2019, 11, 22636-22663.

[152] Li X, Wu B, Chen H, Nan K H, Jin Y Y, Sun L, Wang B L. Recent developments in smart antibacterial surfaces to inhibit biofilm formation and bacterial infections. Journal of Materials Chemistry B, 2018, 6, 4274-4292.

[153] Rajab F H, Korshed P, Liu Z, Wang T, Li L. How did the structural $\mathrm{ZnO}$ nanowire as antibacterial coatings control the switchable wettability? Applied Surface Science, 2019, 469, 593-606.

[154] Lin Z J, Luo G Y, Du W X, Kong T T, Liu C K, Liu Z. Recent advances in microfluidic platforms applied in cancer metastasis: Circulating Tumor Cells' (CTCs) isolation and tumor-on-a-chip. Small, 2020, 16, 1903899.

[155] Li G N, Wang H Y, Zhu Z P, Fan J B, Tian Y, Meng J X, Wang S T. Photo-irresponsive molecule-amplified cell release on photoresponsive nanostructured surfaces. ACS Applied Materials \& Interfaces, 2019, 11, 29681-29688.

[156] Chen C, Zhou L L, Shi L A, Zhu S W, Huang Z C, Xue C, Li J W, Hu Y L, Wu D, Chu J R. Ultralow-voltage-driven smart control of diverse drop's anisotropic sliding by in situ switching joule heat on paraffin-infused microgrooved slippery surface. ACS Applied Materials \& Interfaces, 2020, 12, 1895-1904.

[157] Wei W, Guo J B, Jin L Q, He C, Xie Y, Zhang X, Zhao W F, Zhao C S. Vapor induced phase separation towards anion-/near-infrared-responsive pore channels for switchable anti-fouling membranes. Journal of Materials Chemistry $A, 2020,8,8934-8948$.

[158] Hou S, Zhao H C, Zhao L B, Shen Q L, Wei K S, Suh D Y, Nakao A, Garcia M A, Song M, Lee T. Capture and stimulated release of circulating tumor cells on polymer-grafted silicon nanostructures. Advanced Materials, 2013, 25, $1547-1551$.

[159] Li J T, Kaku T, Tokura Y, Matsukawa K, Homma K, Nishimoto T, Hiruta Y, Akimoto A M, Nagase K, Kanazawa H, Shiratori S. Adsorption, desorption control of fibronectin in real time at the liquid/polymer interface on a quartz crystal microbalance by thermoresponsivity. Biomacromolecules, 2019, 20, 1748-1755.

[160] Yang H T, Li G F, Stansbury J W, Zhu X Q, Wang X, Nie J. Smart antibacterial surface made by photopolymerization. ACS Applied Materials \& Interfaces, 2016, 8, 28047-28054.

[161] Fu Y C, Jin B Y, Zhang Q H, Zhan X L, Chen F Q. $\mathrm{pH}$-induced switchable superwettability of efficient antibacterial fabrics for durable selective oil/water separation. ACS Applied Materials \& Interfaces, 2017, 9, 30161-30170.
[162] Elashnikov R, Slepička P, Rimpelova S, Ulbrich P, Švorčík V, Lyutakov O. Temperature-responsive PLLA/PNIPAM nanofibers for switchable release. Materials Science and Engineering: C, 2017, 72, 293-300.

[163] Liu S H, Fu Y, Li G J, Li L, Law H K, Chen X F, Yan F. Conjugated polymer for voltage-controlled release of molecules. Advanced Materials, 2017, 29, 1701733.

[164] Liu G X, Xu S H, Liu Y Y, Gao Y Y, Tong T, Qi Y C, Zhang C. Flexible drug release device powered by triboelectric nanogenerator. Advanced Functional Materials, 2020, 30, 1909886.

[165] Zhu H, Huang Y, Lou X D, Xia F. Bioinspired superwetting surfaces for biosensing. View, 2020, 2, 20200053.

[166] Gao Z F, Sann E E, Lou X D, Liu R Y, Dai J, Zuo X L, Xia F, Jiang L. Naked-eye point-of-care testing platform based on a pH-responsive superwetting surface: Toward the non-invasive detection of glucose. NPG Asia Materials, 2018, 10, 177-189.

[167] Mutharani B, Ranganathan P, Chen S M, Kannandet R S. Ultrasound-promoted covalent functionalization of CNFs with thermo-sensitive PNIPAM via "grafting-from" strategy for on/off switchable electrochemical determination of clothianidin. Ultrasonics Sonochemistry, 2019, 56, 200-212.

[168] Zhao X, Cui H X, Wang Y, Sun C J, Cui B, Zeng Z H. Development strategies and prospects of nano-based smart pesticide formulation. Journal of Agricultural and Food Chemistry, 2018, 66, 6504-6512.

[169] Gao Y J, Chen C W, Wang D F, Zhang L H, Cai D Q, Wu Z $\mathrm{Y}$. $\mathrm{TiO}_{2} /$ biochar with light-switchable wettability as a herbicide safener and foliar fertilizer adhesive. ACS Sustainable Chemistry \& Engineering, 2020, 8, 1121-1128.

[170] Mutharani B, Ranganathan P, Chen S M, Chen T W, Eldesoky G E, Ali M A, Saikh M W. Temperature-enabled reversible "On/Off" switch-like hazardous herbicide picloram voltammetric sensor in agricultural and environmental samples based on thermo responsive PVCL-tethered MWCNT@Au catalyst. Journal of Hazardous Materials, 2021, 402, 123672.

[171] Calais T, Alvarado P V. Advanced functional materials for soft robotics: Tuning physicochemical properties beyond rigidity control. Multifunctional Materials, 2019, 2, 042001.

[172] Chen Y F, Doshi N, Goldberg B, Wang H Q, Wood R J. Controllable water surface to underwater transition through electrowetting in a hybrid terrestrial-aquatic microrobot. Nature Communications, 2018, 9, 2495.

[173] Li Y, Li J R, Liu L W, Yan Y F, Zhang Q Y, Zhang N, He L L, Liu Y J, Zhang X F, Tian D L, Leng J S, Jiang L. 
Switchable wettability and adhesion of micro/nanostructured elastomer surface via electric field for dynamic liquid droplet manipulation. Advanced Science, 2020, 7, 2000772.

[174] Park J K, Yang Z N, Kim S. Black silicon/elastomer composite surface with switchable wettability and adhesion between lotus and rose petal effects by mechanical strain. ACS Applied Materials \& Interfaces, 2017, 9, 33333-33340.

[175] Wang P, Wang W L, Ci T J, Li L, Han H L. Pump-free oil droplet transfer by combining microfibre array and superoleophobic mesh. Applied Surface Science, 2018, 455, 980-986.

[176] Gao D J, Cao J, Guo Z G. Underwater manipulation of oil droplets and bubbles on superhydrophobic surfaces via switchable adhesion. Chemical Communications, 2019, 55, 3394-3397.
[177] Ludwicki J M, Robinson F L, Steen P H. Switchable wettability for condensation heat transfer. ACS Applied Materials \& Interfaces, 2020, 12, 22115-22119.

[178] Jana N, Parbat D, Mondal B, Das S, Manna U. A biodegradable polymer- based common chemical avenue for optimizing switchable, chemically reactive and tunable adhesive superhydrophobicity. Journal of Materials Chemistry A, 2019, 7, 9120-9129.

[179] Wang Y F, Liang X, Zhu H, Xin J H, Zhang Q, Zhu S P. Reversible water transportation diode: Temperature adaptive smart Janus textile for moisture/thermal management. $A d$ vanced Functional Materials, 2020, 30, 1907851.

[180] Liu Y, Zhao L Y, Lin J J, Yang S K. Electrodeposited surfaces with reversibly switching interfacial properties. Science Advances, 2020, 5, eaax0380. 